\title{
"First Among Shepherds": Terry Pratchett's Tiffany Aching Series from an Arthurian Perspective
}

\author{
By Freya Sacksen
}

A thesis submitted to Victoria University of Wellington in fulfilment of the requirements for a degree in a Master of Arts. 


\section{Table of Contents}

$\begin{array}{ll}\text { Abstract } & 2\end{array}$

$\begin{array}{lr}\text { Acknowledgements } & 3\end{array}$

Introduction $\quad 5$

Chapter 1: Open Your Eyes, Then Open Your Eyes Again 22

Finding the Fisher King $\quad 22$

Time to Thaw: The Witch as Quester 26

The Whole of the Thing: Mystical Kings of the Disc 32

Open Your Eyes: Tiffany As Reversed Fisher King 41

Chapter 2: The Goode Childe's Booke of Faerie Tales 52

The III-Made Knight $\quad 52$

The Arthurian Other and Pratchett $\quad 62$

$\begin{array}{ll}\text { First Sight and Second Thoughts } & 71\end{array}$

Chapter 3: Cracked Mirrors and Melting Girls 83

Tennyson's Inspiration $\quad 83$

The Artist in the Tower $\quad 87$

Light and Shadow: A Close Reading of the Lady of Shalott 91

The Melting Girl: Subversion in the Disc 101

$\begin{array}{lr}\text { Conclusion } & 114\end{array}$

$\begin{array}{lr}\text { Works Cited } & 116\end{array}$ 


\section{Abstract}

Throughout his career writing on the Discworld, Terry Pratchett employed what he referred to as 'white knowledge'; a wide spectrum of intertextuality and allusiveness that pervaded the structure of his stories, the dialogue, the narration, and that was even discussed in scenes constructed to comment on the very absurdity of its existence.

In my MA thesis, I examine closely the allusive qualities of the white knowledge present in Pratchett's Tiffany Aching series: The Wee Free Men (2003), A Hat Full of Sky (2004), Wintersmith (2006), I Shall Wear Midnight (2010) and The Shepherd's Crown (2015). Specifically, I analyze Pratchett's use of the Arthurian tradition and his references to our understanding of the Arthurian tradition, as constructed by Malory, Tennyson and T. H. White. My aim is to demonstrate how Pratchett constructs Tiffany Aching as an Arthurian palimpsest, alluding to what came before whilst subverting and challenging the very texts from which she is imagined.

In my first chapter I analyze the third Tiffany Aching book, Wintersmith, as an example of the Arthurian story of the Fisher King. I also argue for Tiffany Aching herself, in the first two books, existing as a subversive, humanist, reversed Fisher King, who draws strength and power from the land rather than inflicting sterility upon it.

In the second chapter I examine the Arthurian tradition of love triangles, and examine from a feminist, genderqueer perspective Pratchett's habit of placing characters in roles outside of their traditional gender binaries.

In the third chapter I look at Letitia Keepsake, a character introduced in I Shall Wear Midnight, and examine her subversive relationship to the Tennyson poem "The Lady of Shalott". 


\section{Acknowledgements}

This thesis would not exist at all without my deeply patient supervisor, Geoff Miles, who put up gallantly with my constant questions and was always willing to encourage me to take a strange turn in my thinking.

I doubt I would have managed even a fraction of the critical analysis this MA required if not for Catherine Joule with whom I had many an intense argument about Pratchett and the nature of the Disc. At least one argument changed entirely on the basis of something she said.

Angelina Sbroma and Hamish Clayton deserve thanks, the former for her judicial editing and kind words, the latter for his continuous encouragement and reminders.

Harry Ricketts and Sarah Ross for their empathy, patience and kindness.

The Department of Lad Studies: Nick, Alistair, Peter and Tim, for frequently allowing me to complain. Good luck for wherever your studies take you next.

Without the support of my father, Peter Beach, who was unfailing in his belief that not only could I do it, but that I would do it, I doubt I would have made it very far.

My partner, Fisher Rivero, probably put up with more than anybody else; long rants about books he hadn't read, exhausted, terse conversations on academia and editing that I doubt he even came close to parsing. Yet he was always there with a joke, a smile, and a hug for me. When I told him I'd very nearly finished, he was bursting with pride; that carried me through the finish line.

My sister-in-law, Ingrid Beach, and my friend Hamish Cameron, were often on hand to give me advice as my MA neared its end. Knowing I had you there helped.

Also, my brothers, Nick and Lawrence, my sister-in-law Kelly and my nephews, for calmly and wearily putting up with all this talk of academia for the last however many years. I'm sure it was a burden.

And finally, Terry Pratchett himself. The world would be a poorer, less thoughtful place without the Discworld. 
This thesis is dedicated to the memory of my mother

$$
\text { Lisa Valentine Sacksen }
$$

$$
\text { (1951-2017) }
$$

She gave me my first Pratchett to read

and promised me I would go Grailing one day

I doubt this thesis was what she had in mind. 


\section{$\underline{\text { Introduction }}$}

In an undated Usenet article, Terry Pratchett once commented that when it came to references he tried to use what he called "white knowledge" (Breebart and Kew, sec. 52; par. 1), references that any well-read person would be able to pick up the shape of over the course of their lifetime. They might not have read the whole Lord of the Rings (1954-1955), but a joke about a piece of enchanted jewellery being stolen by a muttering ghoul would still have enough of the same shape to make the joke clear; they may not ever have seen Dirty Harry (1971) but Vimes' line in Guards! Guards! (1989) asking a mob if they "feel lucky, punk" would still have the correct shape to recall Dirty Harry's famous speech. ${ }^{1}$

In the introduction to his MA thesis "White Knowledge and the Cauldron of Story", William T. Abbott writes of Pratchett's allusiveness:

White knowledge, the building blocks of knowledge that weave and bind a culture together, creates the best and most important reference base for an author, and Pratchett has tapped it most masterfully. In the process, Pratchett has connected his novels to the reader through the cultural fabric, making them more recognizable and more interesting, whether as parody, satire, pun or general allusion. (6)

Pratchett's tendencies towards allusiveness and intertextuality are sometimes obvious - as, for example, in the title for Monstrous Regiment (2003), which cites John Knox's polemic book against female monarchs (1558) and, incidentally, gives away the book's biggest twist (that almost all the main characters are women in disguise) - and sometimes more subtle, as in the climax to Soul Music (2004) where he references Don

\footnotetext{
1 "I know what you're thinking. 'Did he fire five shots or six?' Well, to tell you the truth, in all the excitement I kind of lost track myself. But being as this is the .44 Magnum, the most powerful handgun in the world and would blow your head clean off, you got to ask yourself one question: 'Do I feel lucky?' Well, do ya punk?" (Dirty Harry)
} 
McLean's "American Pie" (1971). McLean uses 'the day the music died' in reference to the 1959 plane crash which took the lives of Buddy Holly, The Big Bopper and Richie Valens; Pratchett's use of it, however, is literal: in order to save the world, the incarnation of Death must first kill music by playing the chord of silence, and then allow it to be reborn.

The most obvious criticism of most readings of Pratchett's intertextuality particularly in his later novels - will be that of overreading. However, Pratchett's novels have included both structural and subtle references. As an example of structural allusion, in Small Gods (1992), Brutha finds himself stranded in the desert, choosing to forgo meat in order to avoid murder of the helpless. When he returns, he spends some time in a garden, awaiting a fate he knows he cannot escape. Brutha is both Moses of the Old Testament and Jesus of the New. The allusiveness is structural, because the novel's entire narrative depends on this allusion and the recognition of it; an argument might be made for allegory, except that rather than making a one-to-one representation, it is instead a reinvention of the story. It is Moses and Jesus' story as told on the Discworld.

Later texts start creating a narrative in which the intertextual reinvention is instead an intertextual conflict that forms the heart of the story: Carpe Jugulum (1998), a Witches novel, is a conflict between Anne-Rice era vampires (who are beautiful, cruel and use mind control to make characters fall in love with them), and the classic Bram Stoker/Hammer Horror vampires who are violent, but also allow each hero a fighting chance of survival. ${ }^{2}$ Lords and Ladies (1992) also has a conflict as a central theme; however, rather than being between two forces, the conflict is between perception and reality, in this case the perception of elves (referring to how Tolkien and modern fantasy cast elves in a powerfully good light) and the in-text reality of elves (a reference to the folk tales from which Tolkien's elves are derived, and in which they are frequently beautiful, flighty and malicious).

Pratchett also uses intertextuality to engender and then subvert the reader's expectations. Carcer, the main antagonist of Night Watch, invites us to think that the

\footnotetext{
${ }^{2}$ A similar conflict is used in The Fifth Elephant (1999) when discussing Angua's werewolf family who eschew the indiscriminate violence of the classic Hammer Horror monsters and are designed to evoke more the principles of Nazism.
} 
plot is a sort of Les Miserables, with him cast as the fundamentally good but oft-pursued Jean Valjean and Vimes as the intractable-unto-death Javert; however, Carcer's position as a serial killer rather than a protective father alters Pratchett's spin on it. Night Watch is Les Miserables from the perspective of Javert in a world where Javert could be hero, and alters all surrounding characters appropriately. Maskerade (1995) builds its plot structure on The Phantom of the Opera and subverts it by pointing out the one most ridiculous aspect of Phantom: how can you recognize someone who is wearing a mask?

Other books have single scenes structured around an intertextual reference rather than the entire plot. Thief of Time (2001) contains a sequence in which main characters and History Monks Lu-Tze and Lobsang meet a monk named Qu who wants to show them some new devices he's built to help them prevent the Glass Clock being made (or remade, rather). The sequence plays out entirely like a parody of the gadget maker $Q$ in the James Bond series. Soul Music has multiple scene references to the 1980 film The Blues Brothers, starting with a scene at a diner:

"You do fried rat?" said Glod.

"Best damn fried rat in the city," said Gimlet.

"Okay. Give me four fried rats."

"And some dwarf bread," said Imp.

"And some coke," said Lias patiently.

"You mean rat heads or rat legs?"

"No. Four fried rats."

"And some coke."

"You want ketchup on those rats?"

"No." (41)

This references the famous diner scene in The Blues Brothers with Aretha Franklin, where she goes back after receiving their orders and complains that "The tall one wants toast, dry, nothing on it," and "The other one wants four whole fried chickens and a Coke". 
One of the ongoing themes of the Discworld is that influences 'leak' in from our universe; this allows absurdist intertextual references, such as the other reference to The Blues Brothers within Soul Music. This occurs when Cliff and Buddy (as Lias and Imp are then known) steal a piano and briefly run into the Watchman Detritus, and Cliff assures Buddy that "He can't stop us. We're on a mission from Glod."3 (145) The intertextual reference is a nod and wink to the readers who get the joke, but the absurdism of such inter-universe leakage is underlined when characters themselves are puzzled. "Buddy?" asks Cliff a few lines later "Why did I just say dat?" (145).

Pratchett's use of white knowledge is such that on the fan-run website L-Space, there is a Discworld Annotation File that notes, with pagination, every reference Pratchett makes that fans have found, both structural and incidental. It should be noted, such textual and dialogue references as the "four fried rats" scene tend to be far less common in his children's books, due to children's lack of white knowledge. Structural intertextuality tends to be more common.

This all proves that Pratchett's use of intertextuality within structure is complex and multifaceted; while he will occasionally use the same trick twice, it is rarely, if ever, in the same way, and he is fascinated by literature and pop culture, and the way in which we consume and think about them. Given all of this, I feel safe in reading Tiffany Aching's intertextuality from an intentionalist, rather than symptomatic, viewpoint. In other words, I will be examining Pratchett's allusions as if they were intended to be there.

This thesis will discuss Pratchett's use of allusion and intertextuality to form Tiffany Aching and her stories as Arthurian palimpsests.

\section{Intertextuality, Allusion, and the Palimpsest}

The term 'cultural palimpsest' in relation to Pratchett was coined by Gideon Haberkorn in his 2007 journal article "Cultural Palimpsests: Terry Pratchett's New Fantasy Heroes." A palimpsest is defined as a manuscript on which later writing has been superimposed: Haberkorn defines a palimpsest as a reinvention of what has gone

\footnotetext{
3 "They can't stop us; we're on a mission from God" is a repeated line throughout The Blues Brothers.
} 
before: bearing the evidence and traces of what has influenced it whilst at the same time still reacting against it.

Haberkorn uses the term with regards to the concept of Pratchett utilizing the culture of fantasy heroes in the twentieth century to build a palimpsest with his heroes Carrot and Vimes; Haberkorn's specific argument is that Carrot and Vimes, while building on the models of fantasy heroes that have come before, also become, over the course of the novels, rejections of the typical fantasy hero.

In my thesis, I am arguing for the Tiffany Aching books and character as an Arthurian palimpsest, both in the way they draw on the traditions of the Arthurian legend, and in their rejection of Arthurian chivalric values. In order to achieve the palimpsest, there are several narratological devices used: intertextuality and allusion, and to a lesser degree, metonymy and metaphor .

Intertextuality as a term was first invented by the linguist Julia Kristeva in 1969 to describe the means by which texts, languages and semiotic devices exist within a period of historical context; every word and image has a specific historical value to it.

Over time, the word 'intertextual' has come to mean the way in which texts influence, either consciously or unconsciously, later texts within the literary canon. For example in Vladimar Nabokov's Lolita, when Humbert Humbert is explaining his backstory and why he is drawn toward nymphets (as he calls adolescent girls), Nabokov draws heavily from Edgar Allan Poe's poem "Annabel Lee." The effect this has on the text is to establish Humbert Humbert as an unreliable narrator (like the speaker in "Annabel Lee"), and also to set up one of the overriding themes of the novel, that of the romance of literature contrasted against the reality of life: Poe's poem is portrayed as gothic and romantic, but Humbert's excuse which follows the exact same beats is portrayed as pathetic and even morbid.

In Aleksander Rzyman's introduction to his book The Intertextuality of Terry Pratchett's Discworld As A Major Challenge For the Translator, he writes about Gérard Genette's theory of 'hypertextuality':

[Hypertextuality] refers to any type of relationship between a text and some earlier text and at this point 
it sounds a bit 'all-inclusive', yet Genette generally appears to use this term to speak of whole works of literature [...] derived from earlier [...] works, a classic example being Joyce's Ulysses as drawing upon the narrative structure of Homer's Odyssey. (9)

This is precisely the form of structural intertextuality that was highlighted earlier in the introduction with the analysis of Pratchett's structural allusiveness.

María Jesús Martínez Alfaro's work on the origins and development of intertextuality is crucial here; Alfaro's research places Kristeva's work in historical context. This allows the reader to understand the development that has taken place over time for intertextuality to reach its current definition. Alfaro writes:

If Aristotle holds that we learn through imitating others and that our instinct to enjoy works of imitation is an inborn instinct, both Cicero and Quintilian will emphasize later on that imitation is not only a means of forging one's own discourse, but also a consciously intertextual practice that contributes to the definition of the individual. For them, imitation is not repetition but the completion of an act of interpretation. (269)

In other words, to imitate is to reinterpret or reimagine; it is a singularly artistic and critical act. Intertextuality, by its nature, argues against the value of originality, and argues for the value of homage, pastiche, satire.

These arguments together allow us to consider that Pratchett's intertextuality is a form of reinterpretation, and therefore art. Turning a critical eye to his work is to critically consider his art in the context of what has come before and to consider the way we discuss art and artists who build through imitation.

In discussing imitation and artistry, Pratchett's notion of 'white knowledge' rubs up, as Abbott notes, very neatly with J. R. R. Tolkien's concept of the Cauldron of Story: 
Speaking of the history of stories and especially fairy stories we may say that the Pot of Soup, the Cauldron of Story, has always been boiling, and to it have continually added new bits, dainty and undainty. ("On Fairy Stories", 9)

To a certain extent, Tolkien, like Pratchett, is here referring to the narratological idea of the masterplot: the concept that there are story ideas that we recognize and draw on because we have grown up surrounded and enculturated by these stories; that in primitive cultures, we draw on the same sorts of elements to try and explain the world to one another: for instance, that death exists because of a journey; that the seasons exist because of a mourning mother; that fire was stolen and gifted to us.

In the introduction to Narrative Versions, Narrative Theories, Barbara HerrnsteinSmith points out an inherent flaw with the conceptualization of the masterplot, and with all the other aspects of narratology it logically invites in:

I thought especially of [Marian Roalfe Cox's] uneasy feeling, as she intimated in the preface, that if she continued long enough, all stories would turn out to be Cinderella - and my increasing suspicion [...] that Cinderella would turn out to be all stories. (220)

The inherent flaw Herrnstein-Smith refers to here is the notion that after a certain point of time, the capacity to argue for all stories to be some form of masterplot becomes quite appealing but at the same time, quite problematic; at what point do you draw a delineation between these masterplots and these stories? When do you stop? Herrnstein-Smith's suspicion that continuing long enough down this path can lead to a logical end where all stories are one thing, or one thing is all stories, offers at least a glimpse at a point that critics should try not to reach, and an argument against this sort of homogenization of stories, particularly as it pertains to the masterplot. 
The masterplot in narratological terms, specifically refers to the plots of fairy tales and folklore, and so is unhelpful in a study of Pratchett; what masterplots Pratchett uses are drawn from a wide range of sources, including pop culture, high literature, music, art and mythology. Indeed, a lot of Pratchett's humour comes from his intertextual mixing of high-brow references with low-brow ones, such as when he has a Feegle police officer (already a strange enough idea to shock both Tiffany Aching and the rest of the Chalk Hill Feegles) state that he has been watching ballets like Swan on a Hot Tin Roof, ${ }^{4}$ mixing the ballet Swan Lake with the play Cat on a Hot Tin Roof.

Metaphor and metonymy can be seen as two different sides of the coin in terms of linguistics. Metaphor is the direct comparison of two things to serve a specific purpose; for instance, as Tiffany points out in the first book, The Wee Free Men (2003), Miss Tick's statement of Tiffany's ability to find the 'magic school' is a metaphor; there is no 'magic school', all reality is the magic school (303). Granny Weatherwax then adds to the metaphor by saying that magic is like life; you find out that you've passed the test first and then spend all your life finding out why (306). In this sense, Granny Weatherwax refers to the great philosophical questions of life "Why am I here?" and "What do I do with my life?". From her perspective, all of life is one journey toward answering that question, and given that the Tiffany Aching books are structured around Tiffany's growth into maturity and adulthood, it makes sense that those are the questions she is left with at the end of her first adventure.

Metonymy is when something related to an object or event stands in for the whole; a crown standing in for a king; the cross standing in for Jesus' sacrifice; the sovereign standing in for the country. These terms are not the big parts of how this thesis works; they are, appropriately, the small, metaphorical wheels on which it runs, and so need to be explained.

Metonymies and metaphors are useful, because without them, certain parts of the Arthurian, and therefore, I argue, Tiffany Aching's story, would make no sense. If the sovereign doesn't stand in for the country, then the story of the Fisher King makes no sense, because an injury upon the sovereign inflicting famine upon the land would make no narratological sense. If the scabbard isn't a metaphor for a wound, then the story of

\footnotetext{
${ }^{4}$ Terry Pratchett, I Shall Wear Midnight. Doubleday Books, 2010, pg. 179.
} 
Excalibur and the magical properties inherent in both sword and scabbard make no sense, because the scabbard is what heals Arthur and keeps him alive and can only have that property if it is also metaphorical of a wound, so that losing it literally wounds Arthur.

All of this serves to help paint a picture of Pratchett as an intertextual, allusive author. The intertextual, the allusive, and the narratological all work to build up Pratchett's Tiffany Aching as the Arthurian palimpsest.

\section{The Arthurian}

Norris J. Lacy and Geoffrey Ashe's The Arthurian Handbook provides a good starting point for a discussion of the Arthurian mythos and all that it entails, both from a narrative and a critical perspective. The Arthurian includes everything from Uther's conception of Arthur, to the Sword in the Stone, the Round Table, the Holy Grail, Lancelot and Guinevere's love, Mordred's betrayal, and Arthur's final journey to Avalon. Lacy and Ashe open the Handbook with:

The Arthurian legend is multifaceted, a literature in itself, built up by romancers and poets during the Middle Ages in Europe. But it did not expire afterward. Many authors have handled it since, developing its themes or, conversely, turning it into a fairy tale for children. Several modern writers have satirized it, or given it new meanings, or tried to reconstitute a reality underlying it. (3-4)

Lacy and Ashe are fascinated by the myriad ways the Arthurian legend has shifted and developed over the many years since it first started being told; however, I will only be examining a fraction of that story, so only a fraction of their work is needed. This thesis argues that Pratchett is inspired by 'white knowledge' of the Arthurian, rather than any particular retelling. Because of this, the texts I will be drawing on will be largely contemporary in nature. Pratchett is not attempting to write an Arthurian text; he is 
merely drawing on motifs and imagery associated with the Arthurian in the public consciousness, and this has influenced my choice of Arthurian texts. Further, I have also chosen books Pratchett is likely to have read.

The oldest text I will be drawing on will be Malory's Le Morte D'Arthur (1485); it informs the other contemporary texts, and is also a text Pratchett is almost certain to have read. Furthermore, it codifies a great many of the masterplots and narratives we associate with the King Arthur story. By Malory's time, certain plot elements had been set in stone for generations, and Malory ws the one to further elevate them. Arthur's conception via Merlin's magic, and how this sets up Arthur as Uther Pendragon's legitimate heir for when the Sword in the Stone challenge comes many years later, is codified here. Lancelot and Guinevere had been having their romance since the Vulgate Cycles, but Malory establishes Elaine of Carbonek (Galahad's mother) and her rape of Lancelot, as well as Elaine of Astolat and her suicide. Mordred's odd existence, begotten by Arthur, and Arthur's attempt to have Mordred murdered as a child, is also set up here. While the Quest for the Holy Grail, already discussed by multiple authors, is sadly confused in Malory's hands, the fall of Camelot's golden age and Mordred's betrayal are eloquent, and it is here that Malory's villain, Morgana le Fae, finds her redemption, carrying Arthur to Avalon.

I will also be drawing on Tennyson's Idylls of the King and "The Lady of Shalott"; Tennyson is regarded by many critics as responsible for reviving the Victorian interest in the medieval (see: Lacy \& Ashe), and Tennyson uses the imagery of the medieval to make commentary on his contemporary society, comparing Arthur and Guinevere to Victoria and Albert, the nature of the chivalric to the nature of classism and so on. This makes Tennyson an important reference for my thesis, because Pratchett is also using the language and imagery of the Arthurian to comment on his society and the problems endemic to it.

"The Lady of Shalott" is a poem that is central to one of my critical arguments as I will be comparing Letitia Keepsake, a main character from the fourth Tiffany Aching novel, I Shall Wear Midnight, to both the character and her story, and that this is an allusion works to set up several narratological themes. "The Lady of Shalott" draws from the Fair Maid of Astolat story as well as the story of Elaine of Carbonek, Galahad's 
mother. The poem tells of a woman cursed to live in a tower and perceive the world only through a magic mirror, until she spies Lancelot in the mirror, and looks through a window, causing the curse to enact itself and kill her. She dies in a boat on the river and passes, finally, into Camelot.

To a lesser extent, I will be drawing on Robert Browning's "Childe Rowland to the Dark Tower Came" as another exemplar of Victorian medievalism, and for imagery Pratchett may have drawn on. It is a narrative poem that tells of a knight haunted by his dead countrymen, as he journeys to the Dark Tower through a blasted countryside. I will also be drawing from the fairy tale Browning almost certainly drew inspiration from, "Childe Rowlande", about a child kidnapped by the Fae and rescued by their elder sibling after being gifted with advice and a magical sword.

Pratchett utilises the imagery of the chivalric as posited in $I d y l l s$, and uses both the general ideas of the artist-in-the-tower and the lady-in-the-tower in creating Letitia, who is a very clear subversion of the story from "The Lady of Shalott." Some of the language and imagery from Browning's "Childe Rowland" is utilised in the first Tiffany Aching book, The Wee Free Men, which also uses plot points from the original "Childe Rowlande," specifically that of a child being kidnapped by a fairy, and another child having to wander into fairyland and rescue them by decapitating enemies and refusing all offers of food.

As far as twentieth-century literature goes, T. H. White's The Once and Future King has, for many English readers, established the way the story of Arthur goes. White's retelling has been helped along by Disney's interpretation of the first book, and I would be remiss if I did not include it in sources to draw on, especially given how frequently Pratchett references it in both the Watch books and the Tiffany Aching books. T. H. White also frequently makes use of asides to Malory, thereby justifying the inclusion of both in this list. ${ }^{5}$ White codifies many widely held ideas about Arthur's tales, adding that Merlin was a childhood tutor of Arthur's, and the notion that the chivalric code was Arthur attempting to implement some form of restorative justice to the land. White is also responsible for the notion of Merlin's gift of prophecy coming about not

\footnotetext{
${ }^{5}$ White will frequently gloss over an event by referring to Malory, e.g. "If you want to read about the beginning of the Quest for the Grail [...] you must seek them in Malory" (436).
} 
due to a satanic heritage but due to simply travelling backward through time, allowing White to have Merlin comment on White's own anxieties regarding World War II.

The 1981 film Excalibur, ${ }^{6}$ like many film adaptations of the Arthurian story, conflates Excalibur, the Lady of the Lake's gift, with the Sword in the Stone, and uses this to establish its ongoing motif of "The land and the king are one." Though critically panned, it has also been a huge source of help in terms of both a popular Arthurian Fisher King story, tying into my arguments regarding how Pratchett uses the Fisher King, and a general sense of the modern perception of medievalism. To that end, Susan Aronstein's book Hollywood Knights is equally useful in putting Hollywood medievalism into a societal context. Excalibur draws hugely on the myth of the Fisher King in setting up its story, and the Fisher King is an ongoing topic that Pratchett discusses in the Tiffany Aching books in general and in the third Tiffany Aching book, Wintersmith (2006), in particular.

In terms of critical sources relating to the Arthurian, Jessie L. Weston's book From Ritual to Romance on the folkloric origin of the Grail Ritual, and William Nitze's earlier journal articles on it, are important references regarding my arguments about Tiffany Aching and the Fisher King. Due to how deeply it draws on Weston's arguments as well as the Fisher King story, I will also make use of T. S. Eliot's "The Waste Land." Maureen Fries' article on the downfall of Morgana le Fae, "From the Lady to the Tramp," has also been important in helping to pinpoint Pratchett's gender stance, and for this reason I also refer to Sherry B. Ortner's "Is Female to Male as Nature is to Culture" less for its insight into anthropological gender studies, and more for its marvellous metaphor, which I think helps to put the exact narrative work Pratchett is doing in the second book, A Hat Full of Sky (2004), into a clear, concise picture, and especially to allow a contrast with his other work.

\section{Pratchett}

While the field of examining Pratchett from a critical and academic perspective is a relatively young one, this has by no means limited the breadth of the type of academic approaches utilized in examining Pratchett's novels. The critical discussions I have

\footnotetext{
${ }^{6}$ Excalibur. Directed by John Boorman, Orion Pictures, 1981.
} 
chosen are for their comparison of Pratchett's work to either the explicitly medieval or to medievalism, as well as to constructions of palimpsests, rather than those who have examined Pratchett for feminist, narratological or philosophical readings.

Unfortunately, there are no critical theories at the time of writing that combine an examination into Pratchett and his relationship with the Arthurian with the set of books that I am specifically investigating. Due to the huge breadth of Pratchett's work, this is a necessary risk, and I am of the opinion it is more useful to examine work that is close in type to the work that I am doing than necessarily focussing on the same books. The work done by the following theorists proves that my argument is not an outlier, that the comparison between Pratchett and Middle English sources is one worth exploring, and I feel that is more important than investigating critical analyses of the Tiffany Aching books that are totally unconcerned with my specific argument.

Gideon Haberkorn, in his article "Cultural Palimpsests: Terry Pratchett's New Fantasy Heroes", examines how twentieth century fantasy derides civilization and the urban, and how Pratchett's Discworld texts move from parodies of the traditional fantasy elements to rejections of them, particularly through his use of the characters Cohen the Barbarian and Captain Carrot, the long-lost King of Ankh-Morpork who chooses to be a policeman or, as Carrot points out, a 'man of the polis', or city. Haberkorn not only provides the linguistic term I am using to define my argument - that of 'cultural palimpsest' - but the sequence in which Carrot meets Tiffany is one in which we see how far Carrot has come from the 'uncivilized' hero into the canny Watchman, and can contrast that with Tiffany's own development in a different kind of civilization. They are both lost kings ${ }^{7}$ who do not claim a throne for very different reasons.

Rosalind Field also discusses Carrot in the postscript to her piece on "The Curious History of the Matter of England". In a note at the end, she compares Carrot to the Middle English character Havelok the Dane: both are supernaturally strong and charismatic, as well as the heirs to unclaimed thrones (unbeknownst to them both). However, Carrot refuses his throne; in fact he actively works against the people attempting to set him upon it. Interestingly, Field does not draw the line of comparison

\footnotetext{
${ }^{7}$ Tiffany is of course, not literally a king, but I will make an argument for the narrative supporting a reading of her as similar to one.
} 
between Havelok and the Patrician of Ankh-Morpork, whose name, we eventually learn, is Havelock Vetinari ${ }^{8}$. Vetinari (as he is more commonly referred to) and Carrot become unlikely friends - both obsessively fascinated by the city of Ankh-Morpork, and both frequently conspiring together. It is notable that while multiple other characters have a hard time reading Carrot, and Carrot obfuscates his real feelings in front of them, he rarely does so in front of Vetinari, the implication being that the two, in spite of their various differences, are in several ways cut from the same cloth.

While I will not be discussing Captain Carrot, these articles by Haberkorn and Field both help my thesis that Pratchett not only draws from Middle English sources, but that he frequently subverts and rejects the overall message of these inspirational and intertextual sources. Furthermore, Carrot, Vimes, and the rest of the Watch are of use to me because in the fourth Tiffany Aching book, I Shall Wear Midnight, Tiffany interacts with the Watch in a way that indicates a kind of passing of the torch. Not only does she learn, quickly, all of their stories, she also learns all of their secrets. While this could be simply an exercise in making the fans happy, it could also be an exercise in demonstrating likeness: Tiffany's response to the city is very like Carrot's response to the city when he first arrives in Guards! Guards!, one of misunderstanding and naivety. Carrot, in Guards! Guards!, thinks it is his job to arrest the head of the Guild of Thieves; Tiffany thinks she's been locked up in prison, and should be honest that she brought Feegles (the Discworld equivalent of a tribe of small, angry, Glaswegian, nuclear weapons) to Ankh-Morpork. Carrot even wearily asks the more streetwise Mrs Proust to explain "The way of the world" to Tiffany (135).

Imola Bulgozdi responds to Haberkorn's work in “'Some Genetics Are Passed on Via The Soul': The Curious Case of Susan Sto Helit". While Haberkorn specifically focussed on Pratchett's male characters, Bulgozdi specifies that Susan Sto Helit, Death's granddaughter, also functions as a cultural palimpsest, specifically in a rejection of traditional roles for women in fantasy and traditional female stories. She also explicitly rejects Tiffany Aching as a palimpsest, arguing that she is created from bits and pieces of other characters, rather than from an inherited tradition, as Susan and Carrot are. She writes:

\footnotetext{
${ }^{8}$ A pun on the 'Medici' house of Italy.
} 
Susan's fate does not mirror that of Pratchett's most well-known adolescent heroine, Tiffany Aching, whose story follows the much more predictable pattern of a talented young girl educated by older witches. While Tiffany loses her childish belief in magic and learns the rules as she needs to practice witchcraft (Haberkorn and Reinhardt 54), her talent and gender are not questioned the same way Susan's are. (46)

The notion that Pratchett writes his women as rejections of patriarchal fantasy standards is one that I will be explicitly addressing, but I disagree strongly with Bulgozdi's contention that Tiffany is not a palimpsest. Tiffany's gender is a source of continued conflict throughout the novels, from her rejection of sexuality in Wintersmith, to her societal lack of power in I Shall Wear Midnight, and the ways in which these conflicts present themselves show that, as far as society is concerned, Tiffany does not view herself as a 'woman' so much as something outside. Specifically, she views herself as a witch (stating multiple times that people only see the pointy hat). While Tiffany is aware of what she might call 'the facts of life,' she herself is apart from sex and love, and her few romances are devoid of sexual complications. Her demands of the Baron in the fourth book indicate that while she herself is not a landholder, Tiffany regards herself as the Baron's equal. Tiffany's powers are also those that have historically been assigned to masculine protagonists: the powers of analysis and truth-seeking.

Finally, Lucas Boulding's “I Can't Be Having With That': The Ethical Implications of Professional Witchcraft in Pratchett's Fiction" addresses the ethics of having witchcraft as a career and how it functions from both a literary and narrative standpoint. Boulding is fascinated by the philosophy of concepts like narrativium, or the fact that on the Disc, Narrative has replaced Science to the point that magic-users know that to manipulate the narrative is to manipulate the world. Boulding also expresses a philosophical interest in how witches actively choose what stories they become parts of. 
Pratchett's ability to relate stories to reality and how he does this subtly with the witchly powers of First Sight and Second Thoughts will be one of the major parts of my thesis, as Pratchett shows a discontent with the idea of applying narratives to reality. Despite this, Pratchett also shows how the oppressed or those without power may require narratives in order to protect themselves, an aspect Boulding does not touch on.

\section{Primary Texts}

My primary texts for this thesis will be the full Tiffany Aching series: The Wee Free Men (2003), A Hat Full of Sky (2004), Wintersmith (2006), I Shall Wear Midnight (2010) and The Shepherd's Crown (2015). My secondary texts also contain a wide variety of other Discworld and Pratchett texts. I want to specify that although some of these books are the ones published near the end of Pratchett's life, and The Shepherd's Crown is the lone posthumous Discworld book, there will be no discussion of these books as tomes of an ill man or the work of a dying man; that is the work for a different critic, possibly, but I am assuming full intentionality by Pratchett for everything in the pages of the texts. Whether a fuller version of The Shepherd's Crown would have contained a different ending to Letitia's story, or even more Arthurian references is irrelevant; this is the version we have.

\section{Chapter Plans}

In Chapter One, "Open Your Eyes, Then Open Your Eyes Again," I will examine the Arthurian story of the Fisher King, using the work of Jessie L. Weston and William Nitze. In doing so, I will draw comparisons between the Fisher King and the antagonist of the third Tiffany Aching book, Wintersmith. I will also discuss the concept of Pratchett evolving a series of mystical kings over the course of the Discworld in general, and how Tiffany Aching herself fits those moulds, and her own self as a reversed Fisher King. By arguing this, my intent is to discuss Tiffany's relation to the Fisher King story as well as to the concept of the Arthurian Other, and to the stories of the Discworld that have come before her. I will argue that Tiffany Aching represents a logical conclusion from both, as palimpsest of both the Arthurian and the Pratchettian. 
In Chapter Two, "The Goode Childe's Booke of Faerie Tales," I will examine the Tiffany Aching series and characters through the lens of the Arthurian love triangle, starting with some of the relationships Tiffany enters in The Wee Free Men and A Hat Full of Sky. I will examine Pratchett from a feminist and genderqueer perspective, and then build on Lucas Boulding's assumptions of Pratchett as demanding an ethicality to his narratives and to the narratives his characters enter, particularly as regards First Sight and Second Thoughts. All of this will be in an effort to argue that Pratchett is using the Arthurian love triangle as a way to build up an argument against the narrativization of reality, an ongoing theme in the Witches books in general, and in Tiffany's books in particular.

In Chapter Three, "Cracked Mirrors and Melting Girls," I will focus on the last two books, I Shall Wear Midnight and the posthumously published The Shepherd's Crown, examining the character of Letitia Keepsake and comparing her to the Tennyson poem "The Lady of Shalott" as well as examining Tennyson's inspiration for the Arthurian conceit of "The Lady in the Tower" and the common critical interpretation of Tennyson's poem as representing "The Artist in the Tower". I will also do my own close reading of "The Lady of Shalott" and examine how Tiffany and Letitia fit into the poem and what this says about the imagery Pratchett chooses to utilize throughout the poem, and how Pratchett decides to use this imagery to both compare and contrast Letitia to the Lady of Shalott, and what this means for her in The Shepherd's Crown. 


\section{Chapter 1: Open Your Eyes, Then Open Your Eyes Again}

In this chapter I will examine the ways in which the traditional Arthurian tale of the Fisher King can be defined, and how the tale interacts with the Tiffany Aching novel Wintersmith, as well as the ways in which the Discworld presents its own image of mystical kings, and how they, too, form the narrative of Tiffany as the reversed Fisher King.

\section{Finding the Fisher King}

The Fisher King is traditionally the last step in the Grail Quest. He is a king, discovered by the Questing Knight (Gawain, Perceval, Lancelot or Galahad) fishing at a lake - hence his name. He will be infirm, either because of extreme old age, or because of a wound sustained in battle in either the leg or groin. In other words, he is, depending on the author, either metaphorically or literally castrated. Because of his injury and his inability or refusal to rule his land, it has become blasted and a Waste. He is healed usually by the Quester asking a specific Question (usually either "Where is the Grail?" or "Why are you injured?") ${ }^{9}$.

The story of the Fisher King symbolises the connection between King and Land, one that in older civilizations was viewed as integral to the functionality of a nation. This connection is important, because it is not only the entire foundation of the Fisher King story, it is in many ways the entire point of the Fisher King himself. Jessie L. Weston in From Ritual to Romance writes on the Fisher King:
[A]nd [the Fisher King's] infirmity, for some mysterious and unexplained reason, reacts disastrously upon his kingdom, either depriving it of vegetation or exposing it to the ravages of war. (20)

\footnotetext{
${ }^{9}$ Other methods of healing include the medical prowess of Gawain and the mending of a broken sword.
} 
In other words, the Fisher King's infirmity is what leads to the land's Waste: the relationship between the two is one in which the Land is sympathetic to the influence of the King.

In his classic 1909 essay, "The Fisher King in the Grail Romances", William A. Nitze sets out a series of five characteristics that can be used to define the Fisher King character:

1. The name. Nitze notes that there are two particular French titles that are used: roi pêcheur (King Fisherman) and riche pêcheur (Rich Fisherman), and theorizes that the differences stem from a desire to emphasize either the royal side or the fisherman side of the Fisher King's status. Nitze then goes into detail explaining the possible theological allegory behind the Fisher King's status as a fisherman: theologically speaking, fish are associated inherently with the disciple Peter and with Jesus: "Come follow me, Jesus said, 'And I will make you fishers of men'” (KJV, Matthew, 4:19). Furthermore, there is also a link to Celtic mythology with Bran the Blessed, who eats a fish that grants him wisdom.

2. The Fisher King is invariably infirm in some way. His infirmity is brought about either by old age, or by the previously mentioned injury. In Le Morte D'Arthur and Geoffrey Monmouth's Histories, Pelleus is wounded by a wrathful Balan in the thighs, inflicting Waste upon two countries, before Balan is killed by his brother. Nitze goes further in specifying that in some versions of the Grail story (usually versions inspired by the original Perceval), the infirmity is brought about by the Grail Question specifically, by the failure of the Questing Knight to ask it.

3. Nitze also includes the concept of a double or counterpart: this is frequently a son or a brother who awaits the quester, either to explain or exacerbate the connection of the King to the Land. In the original Perceval, it was the King's father who lived in a room, trapped by his old age, subsisting only on the wafers produced by the Grail. In other poems, the character only exists posthumously, brought out on a bier as a symbol of how badly the Waste is affecting the land. Weston views these symbols 
as part of an ongoing dialogue the Grail story has with old rituals of death and rebirth, tying them to such rituals as the Mayday celebrations, in which a straw man would be buried and a Maypole danced around, or the Adonis ritual, where women would weep for the dead Adonis and cut their hair in mourning for him (48).

4. The Fisher King's abode is specified as an otherworldly place, allegorically similar to the journey to the Underworld. Like many of Tennyson's temptations for Percival in Idylls of the King, it exists only for the night, and has vanished by morning. Reaching it is dangerous, and, as mentioned above, it is frequently the last challenge and the climax of the Grail Quest, defining whether the Quester will succeed or not.

5. Finally, Nitze specifies that the Fisher King has a part to play in the Grail Ritual. While the Knight involved is ultimately incidental at this point - after all, it may be his journey, but the journey is not about the knight or the Quester, but about the Grail and the journey the Quester takes - be he Gawain, Galahad, Perceval or Lancelot; the Fisher King and the restoration of his kingdom are the climax of the Ritual. With his health restored, the land is renewed, and the Quest is at an end, as the Knight is rewarded with the Grail; or, alternatively, the Knight fails, and the Waste remains. Narratively speaking, the Fisher King is the emotional climax, focus and resolution of the Grail Quest.

Nitze's definition draws strongly on the Celtic traditions, and is more concerned with the Fisher King as a character than as a story. This is evidenced by the fact that he concerns himself with factors like the Fisher King's name and abode, aspects which aren't all that important to delineating the story. Consider the Disney film The Lion King, in which the lions are shown to have a Fisher King-like relationship with their home the Pride Lands: when good king Mufasa rules, the lands are green, healthy and fecund. When his evil brother Scar takes over (who, notably, sires no cubs, indicating possible sterility), the land becomes a grey Waste, only rejuvenated when the hero Simba banishes Scar and retakes his place as King. There is even a Question answered, much like in a Grail Ritual - "Who killed Mufasa?" Yet most of the aspects that Nitze lists 
here are missing from this narrative, possibly because in more contemporary times, the trope of the Fisher King has started to lose a great deal of the associated story. Instead, the Fisher King has come to mean a story in which the status of the land mimics either the physical or psychological status of a character. Scar, as the villainous murderer, inflicts a famine upon the land, whereas the good Simba returns the land to its former glory.

Weston is more dismissive of Nitze and his definition, being more invested in the potential roots of this story. For Weston it is essential only that the Fisher King's restoration is the purpose of the Quest, and that his sterility is having a magical effect on the land.

I should emphasize at this point that Nitze and Weston are both drawing from older, more traditional Celtic Arthurian traditions. While I don't doubt the possibility of Pratchett having read Perceval or Geoffrey of Monmouth's Histories, as I explained in my introduction, his guiding theme was "white knowledge," and he has described several times putting in references that are not explicit references, but more the idea of the reference. While it might have delighted Pratchett to put in particularly obscure references (and he did on occasion), it is my opinion that Pratchett would attempt to limit his structural sources to those that would be more contemporary so as not to totally alienate his audience. As such, the Fisher King, as part of the Arthurian landscape, fits neatly into Pratchett's definition of 'white knowledge': although every man and woman within Britain might not be able to manage a pitch-perfect retelling of later Arthur stories, the general shape of the Arthur story and aspects like the Fisher King are known; they are narratives of the sort that would fit well in Pratchett's world (as I will argue later).

In defining the Fisher King, I will draw both from Weston and Nitze, as well as the more contemporary Alby Stone and his 1989 article "Bran, Odin and the Fisher King: Norse Traditions and the Grail Legends." I am less interested in where the Arthurian myth and its imagery originates, and more in the effect that returning to it has on an otherwise simple narrative.

My sources are almost all contemporary references, less because Pratchett would be familiar with them, and more because they have come to shape the current generations understanding of the Arthurian. Pratchett would almost certainly be drawing 
on that metonymy in order to shape his narrative. Everybody knows, for instance, that it's always Galahad who wins the Holy Grail even if that's not true, and has only been true since the Vulgate Cycle.

Pratchett usually alters his narrative sources in some way - but in at least one text, the Tiffany Aching book Wintersmith, the Fisher King story is played almost totally straight.

\section{Time to Thaw: The Witch as Quester}

Wintersmith (2006) is the third book in the Tiffany Aching series. Tiffany, a dairymaid from the Chalk living and learning to be a Witch in Lancre, is almost thirteen years old, and working for the rather creepy Miss Treason, who takes her to see the Dark Morris (48-49).

The traditional Morris dance is done to welcome in the spring and summer harvests, with bells and whistles and pipe music; by contrast, the Dark Morris, which is danced only on the Disc, and only in Lancre, is done to welcome in the winter, and is done without music, and with silenced bells and all black costumes, lacking a Fool post. Weston observes a similarity between the Morris dances and the Sword Dances, which she cites as a possible source for the symbology of the Grail Quest, along with the traditional minor arcana of the Tarot deck (the Swords, Cups, Staves and Pentagrams).

Weston wrote about the original Perceval and the action of Wasting:

$[T]$ he woes of the land are directly dependent upon the sickness, or maiming, of the King, and in no wise caused by the failure of the Quester. The 'Wasting of the land' must be held to have been antecedent to that failure, and the Gawain versions in which we find this condition fulfilled are, therefore, prior in origin to the Perceval, in which the 'Wasting' is brought about by the action of the hero, in some versions, indeed, 
has altogether disappeared from the story. (Weston,

63)

Weston is arguing here that it should be taken as read that generally speaking, the Quester has nothing to do with the Wasting of the Land; the exceptions (specifically Perceval) have had little effect on later poems. This argument is found in a chapter on the concept of the Medicine Man, a role Tiffany embodies; the one who comes to heal the Waste, intelligent and gentle in spite of their strength. This is important, because it is Tiffany's act in taking part in the Dark Morris - in the role of the Fool - that sets the plot in motion. Granny Weatherwax implies that Tiffany, due to her connection to the land (which will be discussed later), is blameless in taking part in the Morris. However, both Weatherwax and Tiffany distinguish between 'blameless' and 'responsible': Tiffany might not be to blame for what her feet did, but now that her feet have danced, she must take responsibility for the outcome of this action.

When Tiffany witnesses the Dark Morris, she notices the lack of the traditional Fool post, and attempts to fill the spot by joining the dance without warning:

And then...

...there was someone else there.

It was like the feeling of someone behind her - but it was also the feeling of someone in front of her, and beside her, and above her, and below her, all at once. $[\ldots]$

A voice said: 'Who Are You?' It had an echo, or perhaps two people had said it at the same time. (5152)

This is the moment where Tiffany first interacts with the Wintersmith and Summer Lady, causing instant confusion as she takes the Summer Lady's place ${ }^{10}$, role, and

\footnotetext{
${ }^{10}$ It is not made immediately clear that this is what happens; however, at the end of the book, when Tiffany witnesses the Spring Morris, and sees a character implied to be the Wintersmith occupying the
} 
powers, and metaphorically 'wounds' the Wintersmith by making him lovestruck. This, then, is the Wintersmith's infirmity: he is not castrated or old. Instead, it is a more metaphorical illness. The condition of the Wintersmith is repeatedly referred to as that of a young boy first coming to terms with being in love, flexing his muscles and getting it all wrong, and Tiffany is encouraged to not let him frighten her (256).

In terms of his name, Wintersmith evokes the Fisher King; both have a non-kingly profession attached to them ("smith" and "fisher" respectively), and a modifier that changes its meaning (the Fisher is either Rich or Kingly depending on the poet according to Nitze; the smith does not craft metal but seasons).

In terms of abode, the Wintersmith spends most of the novel without physical form or address, merely chasing after Tiffany; in the climax at the Chalk, Tiffany's homeground and the centre of her power, Wintersmith crafts a palace of ice. Once Tiffany, acting as the Questing Knight, has solved the puzzle of the Wintersmith (in other words, once she has enacted the Wintersmith's version of the Grail Ritual), it melts:

The entire top of the ice palace was melted in a flash of white light that cast shadows on walls a hundred miles away. A pillar of steam roared up, stitched with lightning, and spread out above the world like an umbrella, covering the sun. Then it began to fall back as a soft, warm rain that punched little wormholes in the snow. (382)

Not only does Tiffany melt the Wintersmith's abode, in essence causing it to vanish, in doing so she undoes his wasting of the lands below. His infirmity had led to the freezing over of many lands, from Lancre to the Chalk (although his dialogue indicates he intends to leave parts of the Chalk unfrozen to make Tiffany happy). The 
Wintersmith's intention was to freeze the world over, so that he and Tiffany can be together forever.

This leaves Tiffany not only wearing the shoes of the Summer Lady, destined to banish the Wintersmith for the year, but also in the role of the Questing Knight. In Le Morte D'Arthur, when Galahad goes on his adventure for the Grail, one of the first objects he acquires that symbolises his status as one of the chosen spiritual few, able to gain access to the Holy Grail, is a shield bearing Saint George's Cross. Similarly, Tiffany's silver horse, in the shape of the Chalk's White Horse ${ }^{11}$, acts as her connection to the Wintersmith, and also as both a shield and a sword. In his Idylls of the King, Tennyson writes of Arthur gaining Excalibur:

'There likewise I beheld Excalibur

Before him at his crowning borne, the sword

That rose from out the bosom of the lake,

And Arthur rowed across and took it - rich

With jewels, elfin Urim, on the hilt,

Bewildering heart and eye - the blade so bright

That men are blinded by it - on one side,

Graven in the oldest tongue of all this world,

"Take me," but turn the blade and ye shall see,

And written in the speech ye speak yourself,

"Cast me away!" And sad was Arthur's face

Taking it, but old Merlin counselled him,

"Take thou and strike! The time to cast away

Is yet far-off." So this great brand the king

Took and by this will beat his foemen down.' (The

Coming of Arthur, lines 296-310)

It is interesting that Tennyson describes the sword as a 'brand', because what causes Tiffany's silver horse to have a connection both to Tiffany herself and to the Wintersmith

${ }^{11}$ Itself based on the White Horse of Uffington. (A Hat Full of Sky, 351) 
is the fact that it brands her. After Tiffany loses the silver horse at the Dark Morris, the Wintersmith comes to return it, holding it out on an icy morning:

Take it. It's part of who you are. Take it. When you hold it you think of home. Take it!

She held out her right hand.

The horse dropped into it. It was indeed colder than she could have imagined, and it burned. (81-82)

This is yet another example of Pratchett's wordplay, for earlier he described Tiffany's relationship to the horse as being like a knight donning their armour (22). Since 'brand' can mean both sword and something hot that burns a mark in the flesh, Pratchett is clearly invoking this particular wordplay.

If we accept the white horse as Tiffany's Excalibur, then the above quote evokes the 'take me' part of the poem. The 'cast away' comes later, when Tiffany must abandon the horse to try and avoid the Wintersmith being able to find her:

Now Granny Weatherwax stood on the bridge, the silver horse in her hand.

"It's the only way," she said. "It'll end up at the bottom of the deep sea. Let the wintersmith look for you there!" (190)

In most versions of Arthur's death, he must ask the attending knight to throw his sword away three times, and when he does, it is caught by the Lady of the Lake, rising up from the shallows (a similar event happens with Roland and the Feegles in the Underworld in the same novel). ${ }^{12}$ Tiffany's casting aside of her beloved silver horse does not take three attempts. It does, however, show up later, when Tiffany's younger brother catches a pike and Tiffany finds it in the fish's mouth. The instant Tiffany places

\footnotetext{
12 "Just before [the sword] hit the water a white arm rose and caught it. The hand waved the sword a couple of times, and then disappeared with it under the water." (369)
} 
her hand on it, the Wintersmith finds her, and the Chalk becomes a snowy Waste (348349). Because of the effect of Tiffany placing her hand upon the horse, this scene, like the Wintersmith mistaking Tiffany for the Summer Lady earlier in the novel, can also be read as an act of sterility and cause of Waste. This speaks to Weston's definition of the Fisher King, in which he is connected to the fecundity/sterility of the land, and in which asking the right Question is what allows the land to become abundant again. ${ }^{13}$

While Tiffany attempts to save the sheep and lambs from the Wintersmith's blizzard, Roland and the Nac Mac Feegle head into the underworld to rescue the Summer Lady. As Nitze notes, most abodes of the Fisher King are allegorically similar to underworlds, so Roland and the Nac Mac Feegle enacting an Orpheus story is appropriate. It's also appropriate that Roland awakens the Summer Lady (who has taken on the form of Tiffany, the girl Roland has a crush on) with a kiss (374), given how Tiffany deals with the Wintersmith when she is finally his captive:

"I am winter. I cannot be anything else."

"Then you cannot be human," said Tiffany. "The last three lines [of the song] ${ }^{14}$ are: 'Strength enough to build a home, Time enough to hold a child, Love enough to break a heart'." $[\ldots]$

Balance....and the old kelda had once told her:

'There's a wee bit o' you that willnae melt and flow.'

Time to thaw.

She shut her eyes and kissed the wintersmith...

\footnotetext{
${ }^{13}$ As mentioned earlier, Weston also draws a connection between the symbolism of the Fisher King and Tarot symbology (the grail, lance and dish all linking to the Minor Arcana). Pratchett has already demonstrated knowledge of Tarot by parodying it in earlier books with the Caroc cards. Tiffany draws power from the symbol of the horse, which within the Major Arcana of the Rider-Waite (frequently cited as the most commonly recognized Tarot deck in the English-speaking world) Tarot appears only within two cards: Death and the Sun. While the Death card symbolises change, the Sun symbolises optimism and enlightenment, which Tiffany attains by the end of the novel. Either way, both of these cards' literal meanings come into play in Tiffany's banishing of the Wintersmith: she kisses him, draws down the sun, and he is melted away.

${ }^{14}$ The Wintersmith uses the lyrics of a song of Pratchett's devising listing the chemical composition of a human in order to make a human form; however the last three lines, listing the abstract composition of a human's soul, confuse him for having "no substance" (380)
} 
....and drew down the sun. (380-382)

In kissing the Summer Lady and the Wintersmith, Roland and Tiffany restore their Chalk from Waste to its natural state, and Tiffany is able to return the Summer Lady's status as goddess to her. It is interesting to note that, just as Tiffany intends to melt the Wintersmith and, in this way, also the Chalk, she notes that she, too, will thaw, a metaphor for allowing herself grief for the Wintersmith.

In summary, following Tiffany's dance at the Dark Morris, the Wintersmith becomes the Fisher King for the Chalk, wounded metaphorically by his teenage crush on Tiffany. In response, the protagonist witch takes on the role of Questing Knight, meeting all the requirements of the definition as set out above: the name, the abode, the ritual, the double and the Wintersmith/Fisher King's infirmity.

\section{The Whole of the Thing: Mystical Kings of the Disc}

When examining the Fisher King, we encounter again and again a set of rules and definitions for how the Fisher King story and character exist. As time goes on and Pratchett expands the Disc canon, he also sets out his own set of rules and definitions regarding what I am going to refer to as the Disc's mystical kings; these are worthy of contrast and comparison. To that end, I will be discussing the ways in which Tiffany Aching is neither a typical Disc mystical king, nor a typical Arthurian Fisher King.

Mystical kings is not a perfect term, for most of the entities are not literal 'kings'; rather, they are characterised as having dominion over something. Pratchett is far more interested in the idea of people as dominion than land as dominion, so mystical kings in the Disc are those with dominion over people. For instance, Havelock Vetinari, current undisputed ruler of Ankh-Morpork, and Captain Carrot, secret heir to the mouldering throne of that city, are discussed far more with relation to Ankh-Morpork's people in general terms than they ever are with Ankh-Morpork's actual, physical landscape. Commander Vimes, who is famous for being the descendent of (thus far) the only man to execute a king, has a much more tangible relationship with the land (being able to tell where he is in Ankh-Morpork through the soles of his feet) and with its people (paying 
the widows and children of dead Watchmen from his own paycheck before a widow's pension is set up in Men At Arms (196-198)).

What makes Disc's mystical kings mystical is their inherent association with the supernatural. Despite the occasional hints that maybe Vetinari is something other than human, he displays no real supernatural abilities other than an astonishing amount of intelligence and raw cunning. Contrast Captain Carrot, who is supernaturally charismatic, lucky, manipulative, likeable and good. In an Arthurian work, Captain Carrot would not labour as a Watchman long; the instant it was revealed that he was the heir to the throne, Vetinari would be overthrown, and Carrot would be the good and rightful King of Ankh-Morpork. Both Harberkorn and Fields discuss the case of Carrot in contrast to the typical rules of fantasy, Harberkorn as a cultural palimpsest in "Cultural Palimpsests: Terry Pratchett's New Fantasy Heroes", and Fields as a reaction to the EME (Early Modern English) piece Havelok the Dane in "The Curious History of the Matter of England"; both come to the conclusion Pratchett is attempting a subversion of the traditional fantasy expectation. After all, Carrot may share many traits in common with Havelok - Fields notes their supernatural charisma and strength (40-41) - but he is also distinctly a man of the people, as Harberkorn argues (334), unlike many a fantasy hero is expected to be. Here we start to encounter Pratchett's rules, and many of them run opposite to the rules and tropes of Arthurian lore.

Consider the god Om as a mystical king of the Omnians. Kings and gods are frequently interchangeable, to the point that we refer to kings as ruling 'by divine decree'; Frazer writes in The Golden Bough of the Divine Kings of Peru "[A]s children of the Sun the Incas of Peru were revered like gods; they could do no wrong, and no one dreamed of offending [...] the monarch or of any of the royal race. [...] They considered [sickness] a messenger from their father the Sun to call them to come and rest with him in Heaven" (415), drawing a link between gods and kings, and making them interchangeable. Ergo, any rule a king lays down is done in God's name and favour. This logic extends somewhat further in the Disc, where gods only exist because people believe in them, just as kings only exist because people live in their kingdom. When Om arrives to choose his next prophet, in Small Gods, he is dismayed to find that he has taken on the form of a one-eyed malnourished tortoise (19), due to the fact that religion 
and ritual have replaced belief and only one person believes in him anymore: the simple, illiterate Novice Brutha (137).

This faltering of belief becomes Om's Waste; Om is, in many ways, a Fisher King throughout Small Gods. He is the victim of his own religion, and of Vorbis, head of the Quisition and self-declared Eighth Prophet (215). In particular, Vorbis' interpretation of the Omnian faith causes Om's followers to have a stronger investment in Vorbis' lies, practices and ceremonies than in Om's faith. It is only when Om kills Vorbis, through being launched at his head by an eagle, just as Vorbis is about to slay Brutha (in a sequence deliberately designed to evoke the crucifixion of Jesus), that Om's followers return to him (243-248). However, Om is forced to negotiate with his own prophet:

\author{
XI. There Must Be Punishment! Otherwise There Will \\ Be No Order! \\ "No." \\ XII. I Do Not Need You! I Have Believers Enough \\ Now! \\ "But only through me. And, perhaps, not for long. It \\ will all happen again. It's happened before. It happens \\ all the time. That's why gods die. They never believe \\ in people. But you have a chance. All you need to do \\ is...believe." (250)
}

In this sequence, Brutha is telling Om that if Om does not wish to return to having a situation like that of the beginning of the book, he needs to listen to the prayers of his people, and answer them, rather than merely bask in their belief. He needs to watch over his people as his children. He is asked, in other words, to be the good shepherd.

This sets up Pratchett's first rule: his mystical kings are not metaphors, figureheads or dei ex machina: they, like his protagonists, are characters, subject to change. In the Arthurian legends, Arthur's stories and viewpoint are rarely granted to us outside of him gaining the crown and losing it; he is very like the chief in a police procedural, offering jobs to his knights, and his personality is very dependent on what is 
happening in the story. Compare the Arthur in Gawain and the Green Knight (a partying fool) to the Arthur in the opening chapters of the Holy Grail as written by Malory (a tired king, worried about how many knights he will lose on the endeavour) to the Arthur in T. $\mathrm{H}$. White's The Once and Future King, who gradually develops into a stand-in for White's fears concerning World War II. His personality is extremely dependent on his author; unlike his knights, who all have established personality traits (Lancelot is good but flawed; Kay is rude and tactless; Gawain is sometimes brutal but always noble; Galahad is pure and chaste and so on), Arthur's only defining trait is that he is a Good King - which results in a rather bland personality. Pratchett's mystical kings, on the other hand, have a bevy of flaws to work through: Om starts off vicious, judgemental, and self-centred, the very embodiment of an Old Testament deity, before learning slowly to empathize with the creatures who worship him and becoming a noble, intelligent god, willing to fight for his believers. The best that can be said about Arthur is that, in his blandness, writers and readers can project their definition of a Good King onto him - much like how Aphrodite's appearance is never described, or how Lovecraft avoids describing his 'nameless horrors'; the readers will never agree with the author on what a 'Good King', a 'beautiful woman' or a 'nameless horror' should be, so the authors all leave it up to them, resulting in, occasionally, rather beige prose. Pratchett avoids this, and even, to a certain extent, mocks it.

Contrasting somewhat with Small Gods is Monstrous Regiment (2003), a nonseries Disc novel taking place in Borogravia, a country that, due to a combination of religion and local politics, is in a generations-long war with their larger and more advanced neighbour, Zlobenia. Borogravia has two national deities. One is Nuggan, a demonstration of what happens to a god if it doesn't go through the character arc Om has in Small Gods. Nuggan has a living testament that updates with new Abominations regularly (22). Near the end of the book, when the main character is discussing the future of Borogravia with Vimes, Nuggan's status as an insane god is discussed:

"You know your god's dead?" said the man. "Nothing left but a voice according to some of our priests. The 
last three Abominations were against rocks, ears and accordion players.["] (326)

Nuggan is dead because he has lost all of his believers, something Om is terrified of in Small Gods. This is because all of the belief has instead been going to the long-dead Duchess Annagovia, ruler of Borogravia (23-24). The Duchess has enough raw belief by the end of the novel to make an appearance, possessing one of the main characters, and urging the Borogravian High Command to put an end to the war:

"I see heroes!" said the Duchess, staring at the tableau of officers. "All of you gave up...much. But I demand more. Much more. Is there any amongst you who for the sake of my memory will not die in battle?" Wazzer's head turned and looked along the row. "No. I see there is not. And now I demand that you do what the ignorant might feel is the easier thing. You must refrain from dying in battle. Revenge is not redress. Revenge is a wheel, and it turns backwards. The dead are not your masters." (317)

I quote this section because it is an interesting counterpoint to Small Gods, where Om does basically the same thing, just on a larger scale. However, the difference is that Om has come to understand that the people who need to be convinced not to go to war are the people with power, or the people who on the Disc have real power: the proletariat; the soldiers; the day-to-day officers; the people, in other words, who have no stake in the war. The Duchess, being an upper class woman, appeals to the High Command people long since removed from the realities of warfare who do have a stake in the warfare - hence, why, six months after the truce, main characters Polly and Maladicta find themselves making their way back to the front (351).

This ties into the second rule of mystical kings: they are only as powerful as their followers allow. The Duchess can only have as much power over the High Command as 
the High Command grants; Om can only have as much power over his believers as they willingly grant him through belief; King Verence of Lancre is continually attempting to modernize Lancre for the coming century, and is continually merely humoured by his people; the Witches of Lancre are only ever as powerful as the amount of respect they command, both from the people on their steading and from the other Witches. And this power can be misused: Nuggan's inability to move past his Abominations causes his insanity and death; the Duchess's inability to see past her own class values prevents peace from truly coming to Borogravia.

Contrast this to Arthurian legend, where civilians aren't ever named characters. We're told many times that Arthur is the Good King of Britain, and that he will rise to rule again, but the only evidence we see of Arthur's 'Goodness' is his sending his knights out to do good deeds, and these good deeds deal almost solely with the nobility. Peasantry are never dealt with in depth; to the extent that they exist, they are background scenery. That said, there is an element of Arthur's power as a leader being tied to his knights that starts to wane as time goes on, with an outright attempted assassination taking place in his home, for which Guinevere is blamed. The fact that Mordred works to subvert Arthur's leadership is a strange addition to the story of the Poisoned Apple, and seems to imply that Arthur's true dominion is neither Britain nor her peoples but instead his knights.

In defining the third rule of mystical kings, an excellent example presents in the coronation ceremony for the Low King of the dwarfs in The Fifth Elephant. It involves being crowned upon the Scone of Stone ${ }^{15}$ (a clear reference to the real-life Stone of Scone), which is claimed to be fifteen hundred years old (40), and still has not only the imprint of the first dwarf King, B'hrian Bloodaxe, but also still contains the piece of truth stolen at the beginning of the world (295-296). It is referred to as "the thing and the whole of the thing" (44). While the Scone itself is not a mystical king, Rhys Rhysson, the Low King of the dwarfs being crowned, is, if only for his understanding of the Scone. The plot of the book revolves around the destruction of the original Scone, and a replica Scone being made, all in an attempt to throw the dwarfs into civil war, which Rhys

\footnotetext{
${ }^{15}$ A long-running multi-book joke in the Discworld series is that Dwarf bakery is so akin to rock as to be used as a battle weapon.
} 
Rhysson would no doubt lose to his competitor, Albrecht Albrechtsson, who has said he will declare Ankh-Morpork dwarfs d'harak, or 'not subject to dwarf law' $(245,247)$. At the climax of the book, the replica Scone is brought forth, and Rhys and Albrecht both declare it "The thing and the whole of the thing" (402). When Vimes is confused, Rhys takes him aside and explains:

"I think I will tell you this because, your excellency, I really do not want you going through the rest of your time here asking silly questions. Yes, this is the true Scone."

"But how could -"

"Wait! So was the one that is, yes, ground to dust in the cave by Dee in her...madness," the King went on. "So were the...let me see...five before that. Still untouched by time after fifteen hundred years? What romantics we dwarfs are! Even the very best dwarf bread crumbles after a few hundred." (409)

In other words, what Rhys is establishing here is the rule that belief is more important than legitimacy. He continues by citing the grandfather's axe paradox ${ }^{16}$ ("This milord, is my family's axe. We have owned it for almost nine hundred years now. Of course, sometimes it needed a new blade. And sometimes it has required a new handle [...] but is this not the nine-hundred year old axe of my family?" (409) ).

While the first rule of mystical kings on the Discworld is something that is clearly not Arthurian and the second rule might be argued to sometimes be Arthurian, this dismissal of legitimacy is something that would never be found in an Arthurian text. Arthur is King of England because he is Uther's legitimate heir. Galahad is the greatest knight of all time because he is Lancelot's legitimate heir. Both of them answer legitimate challenges. Falsehoods are things that only Morgana le Fae or Mordred deal in. When Guinevere is innocent, Lancelot can save her; when she is guilty, she receives

\footnotetext{
${ }^{16}$ Sometimes referred to as the Theseus' Ship Paradox.
} 
her sentence and goes to her execution, and Lancelot wrongfully (but romantically) betrays his king and country to rescue her from the pyre, bringing about the end of Arthur's reign as king. Only Excalibur and its scabbard can save Arthur, and both are lost by the end of the story. All of these stories revolve around legitimacy and its importance to the chivalric romance.

Pratchett, on the other hand, buys heavily into the falsehood of miracles. Legitimacy and purity are, ultimately, totally ineffective against belief. In Maskerade (1995), a Discworld retelling of the Phantom of the Opera story, Granny Weatherwax figures out that there are two masked Opera House Ghosts running about the Opera (291); one giving singing lessons and watching performances (83), and the other killing people (57). The murderer turns out to be Salzella, an opera director driven mad by the theatrics of theatre work (288); the songster is the janitor known as Walter Plinge, ${ }^{17}$ who without his mask is a rather simple creature (284). Granny offers him an invisible, imaginary mask, and upon donning it, Walter becomes the Opera House Ghost permanently (290-291). There is no mask, merely the belief in one, which, on the Disc, is so very much more important.

The final aspect of the mystical kings of the Disc is, as l've touched on briefly with the choice to call them mystical, the subject of their supernaturalness. Mystical kings on the Disc frequently belong to the Other, and the Other is not always the supernatural. They are separate in some ways from their peers, by gender, identity, destiny, choice, or a mix of the above. For example, dwarfs do not separate the sexes; it is frequently noted that dwarfish courting involves delicately attempting to ascertain the gender of the other. That is until Feet of Clay, when Cheri (previously Cheery) Littlebottom starts dressing as a female, outwardly stating her gender for the world. However, this does lead to her Othering, to her separating herself out from the default male dwarfish stereotype. In The Fifth Elephant, she is repeatedly referred to as 'ha'ak' (which, from context in this and other books, we can assume means something along the lines of 'defiler of all that is dwarfish' - in other words, she is something Other and worse than dwarfish). The Fifth Elephant also implies - and later books confirm - that

\footnotetext{
17 The Annotated Pratchett file notes that Walter Plinge is a generic pseudonym used by actors who play two roles in the same play; an appropriate name for a janitor who is also a Phantom.

(https://www.lspace.org/books/apf/maskerade.html)
} 
Low King Rhys Rhysson is in fact a female dwarf wanting to exist as out (449). In other words, Rhys Rhysson belongs to the Other.

Another, more dramatic example, is that of Thud! where we are introduced to the concept of troll kings in the shape of Mr. Shine. Trolls in the Discworld are made of metamorphorical rock, a portmanteau of metaphorical and metamorphic; the trolls, in other words, are composed of the rock that gives them their name. So we get Carborundum, Detritus, Chalky, Brick, and so on. Their teeth are diamond and their brains silicon, meaning that, like computers with broken cooling systems, they slow down and get stupider the hotter they get (most wild trolls are said to live up in the mountains). Troll kings, however, are composed of diamond, allowing them to reflect heat away from their surface, making them constantly intelligent, and destined for kingship (269). As Ankh-Morpork plunges into near-street warfare with the upcoming Koom Valley ${ }^{18}$ Remembrance Day celebrations, more and more trolls graffiti walls with "Mr. Shine, Him Diamond!"; possibly as a way of anxiously requesting his aid, or as a way of invoking him as an almost totemic leader in a time of great stress (224). Shine is both part of and apart from the troll community.

King Arthur might be considered part of the Other; his closest confidant is Merlin, and his half-sister is the witch Morgana le Fae (in many versions), so he is certainly touched by something without. However, so few stories tell Arthur's perspective that it's difficult to know, and the Fisher King, while a character in his own right, is also ultimately an obstacle to be overcome. Within a narrative structure, part of the purpose of Othering is to affect the reader's perception of the character and the motives: the revelation that Rhys is desiring to become part of the outed dwarf female community alters the reader's perception of all of Rhys' interactions with Cheery and Ankh-Morpork up to that point; Mr. Shine's Otherly qualities allow him to stand apart from and empathize with his community, as well as provide a foil to the more hotheaded Vimes; when Vimes asks why he helped drug addict Brick, Mr. Shine responds with "Why should you care about some dead dwarfs?" Vimes' answer, "Because someone has to!"

\footnotetext{
${ }^{18}$ Koom Valley is a battle between the trolls and the dwarfs - it starts off as a gag about the one time that two sides managed to ambush each other, until Thud!, where Pratchett spends a whole book examining how war affects racial tensions and racial narratives and the rewriting of said narratives. Koom Valley is used, for much of the book, as an excuse for why the trolls hate the dwarfs and why the dwarfs hate the trolls.
} 
speaks for both of them (275-276). But without a focalizing perspective or revelatory moment, Arthur's Otherness in no way alters or changes the textual perception of him. Furthermore, Arthur rarely expresses any emotion towards his engagement with the Other. Mr. Shine is at peace with his Otherness because he knows his destiny and he has a purpose; Rhys Rhysson actively chooses to other herself because she believes in the liberation movement Cheri Littlebottom represents. To the extent that Arthur is Othered, he never has any emotion about it.

In conclusion, Pratchett's Disc has several rules that define its mystical kings, sometimes in contrast to the Arthurian. These rules are:

1. The domains of mystical kings are frequently people, not land, though this is not an ironclad rule (see: Lancre, Vimes' relationship with AnkhMorpork, etc.)

2. Mystical kings, like protagonists, are characters that grow and develop and change over time.

3. Such kings are only ever as powerful as their followers allow.

4. Legitimacy and purity are less important than belief and effectiveness.

5. All mystical kings are somewhat supernatural; they all also belong to the other. These may be the same thing; frequently, they are not.

\section{Open Your Eyes: Tiffany As Reversed Fisher King}

Combining the above definition of the mystical kings of the Disc with Nitze and Weston's definitions of the Fisher King, I now present Tiffany as a reversed Fisher King: that is, a Fisher King who is empowered by her land's fecundity, rather than inflicting it with sterility due to an injury.

Before defining Tiffany, it is important to look at the Witch of the Chalk who comes before Tiffany and the events of The Wee Free Men - specifically, her grandmother, Granny Aching. Tiffany in The Wee Free Men perceives the Chalk and the world through the lens of her grandmother and her grief over her grandmother's death, but there are also elements that point towards Granny Aching having possessed a straight Fisher King relationship with her steading the Chalk: 
Granny had smiled at the horizon, puffed at her pipe for a while, and replied: "A man who takes arms against his lord, that man is hanged. A starving man who steals his lord's sheep, that man is hanged. A dog that kills sheep, that dog is put to death. Those laws are on these hills and these hills are in my bones. What is a baron, that the law be brake for him?" (Pratchett, 95-96)

These laws are so old no man remembers from whence they came; however, Granny Aching breaks them not for the sake of mere money but the Baron's word. When an unfair ruling looks to be passed on an innocent, if slightly confused, woman, Granny Aching reminds the Baron of the word he gave, and he finds a different solution (238239).

Granny Aching's relationship with the Chalk can also be seen in how Tiffany describes the day of her death:

...the hills had been silent on the day Granny Aching died.

$[\ldots]$

It was no longer the silence of many little noises, but a dome of quiet all around the hut.

She knew then, even before she went in at the open door and found Granny lying on the narrow bed. (148)

The fact that the silence on the wold (the area of the Chalk where both Granny and the Nac Mac Feegle live) responds to Granny's death is representative of how Tiffany and the Chalk perceive her grandmother, positing her as a Fisher King type. This is reinforced at the climax of the book, when Tiffany experiences the full history of the 
Chalk, and has this revelation: "Someone has to care. Sometimes, they have to fight. Someone has to speak for that which has no voice..." (281). ${ }^{19}$

It is at this point that Tiffany begins to step into her role of Fisher King, a role that is reversed from the norm. Both Weston and Nitze specify that the Fisher King is defined at least partially by the fact that it is his infirmity that causes the Waste upon the land. In Tiffany's case, rather than inflicting sterility upon her land, she is empowered by her home's fecundity and abundance. This is most evident in the first two books, when Tiffany, as instructed by Miss Tick, the first witch she meets, opens her eyes, and opens her eyes again: ${ }^{20}$

...and then, like someone rising from the clouds of a sleep, she felt the deep, deep Time below her. She sensed the breath of the downs and the distant roar of ancient, ancient seas trapped in millions of tiny shells. She thought of Granny Aching, under the turf, becoming part of the chalk again, part of the land under wave. She felt as if huge wheels, of time and stars, were turning slowly around her.

She opened her eyes and then, somewhere inside, she opened her eyes again. (290)

The opening of Tiffany's eyes is tied to her relationship with the Chalk. When she opens her eyes and opens her eyes again, she is empowered totally and utterly by her land, by its health and growth, as well as its history and her knowledge of herself. This is the reversal mentioned above: whereas the Fisher King is a relationship in which the land is sympathetic to the king - he is injured, therefore the land is injured - Tiffany's relationship with the land functions in the opposite manner: the land is healthy and strong, therefore Tiffany may borrow that strength.

\footnotetext{
${ }^{19}$ This is a reworded version of what Granny Aching tells the young Tiffany: "Them as can do, has to do for them as can't. And someone has to speak up for them as has no voices" (196).

${ }^{20}$ When Tiffany meets Miss Tick, the Witchfinder, she is informed that to find the magic school of Witches she must 'open her eyes, and then open her eyes again'. This action corresponds to a connection to the world, and the revelation of its inherent magical power.
} 
Both Weston and Nitze spend some time with the Fisher King's name, speaking about how it ties into Biblical themes of "Follow me and I will make ye fishers of men" (KJV Matthew 4:19) as well as the Celtic conceit of the fish representing knowledge. Tiffany's own name is important within the text for its' own reason, and is returned to many times:

$[T]$ he round face became a mass of lines as the kelda smiled. "What was your name, now?"

"Tiffany, er, Kelda." [...]

"A good name. In our tongue you'd be Tir-far-thóinn, Land Under Wave," said the kelda. It sounded like 'Tiffan'. (138)

The 'Land Under Wave' is used to describe both Tiffany and the Chalk, meaning we are led to believe that the two, to a greater or lesser extent, are interchangeable, just as Tiffany's Granny Aching referred to herself and the land as interchangeable.

There is also the matter of kingship. Tiffany and her grandmother are both shepherds, which has its own Biblical allusions, allusions which are referenced in Small Gods (230). When Om goes to Dunmanifestin, the home of the gods, he tells a mathematically challenged god that fifty is a lot less than fifty-one (i.e. it is never worth it to lose one follower) and that one is the same as a thousand (one follower is worth the same as a thousand). However, the book also criticizes Om's religion for being built by shepherds rather than goatherds, because sheep must be herded while goats must be led. Interestingly, although Tiffany likes sheep quite a lot and works with them frequently, she also spends the second book dealing with a herd of goats and discussing how with goats you need to 'win'. Her working as both a shepherd and goatherd indicates that she is able to act as 'the good shepherd', herding those who are meek and frightened, whilst also indicating her ability to lead those who are more stubborn and with more brains (Pratchett explicitly describes goats in A Hat Full of Sky as "worrying [...] if you were used to sheep because a goat is a sheep with brains" (88)), hinting at her eventual future as Granny Weatherwax's successor as the head of witchcraft. 
The same idea - the concept of 'the good shepherd' - is embodied rather more literally in Granny Aching, who becomes something like Tiffany's moral compass. The refrain 'Granny Aching never lost a sheep' is what Tiffany frequently uses to decide how she should act. Furthermore, Tiffany's father seems to put forward the theory that as far as the land is concerned, they are the rightful rulers of the land:

It was actually called the Home Farm. Her father rented it from the Baron, who owned the land, but there had been Achings farming it for hundreds of years and so, her father said [...] as far as the land knew, it was owned by the Achings. (17)

This presents the concept of shepherd-as-king, and allows us to start viewing Tiffany as a reversed Fisher King not just in symbol, but also in terms of her narrative as a mystical monarch of the Disc.

As mentioned earlier, Tiffany's enactment of the reversed Fisher King is only truly fulfilled in the first two books she appears in. In The Wee Free Men she continually examines her relationship with the Chalk's previous Fisher King Granny Aching as she turns back an incursion of Elves, and vows to journey into Lancre to learn how to be a witch, to protect her country, despite their hatred of witches:

There, glistening on the oily, rich yellow surface [of the butter] was a gibbous moon and, sailing in front of the moon, a witch on a broomstick.

She smiled again, and it was Granny Aching's smile.

Things would be different one day.

But you had to start small, like oak trees. (317-318)

Nitze notes that traditionally, Fisher Kings' abodes vanish by morning, and compares the journey there to the journey to the underworld. In The Wee Free Men, the 
journey through the Queen's world can easily be described as similar to the journey undertaken by Roland in Browning's poem "Childe Roland To The Dark Tower Came":

No! Penury, inertness and grimace, In the strange sort, were the land's portion. "See Or shut your eyes," said Nature peevishly, "It nothing skills: I cannot help my case:

' $T$ is the Last Judgement's fire must cure this place, Calcine its clods and set my prisoners free." (Browning, lines 61-66)

Compare the above to Tiffany's description of the Queen's world:

The trees here, though, were different. She had a strong feeling that they were blobs, and were growing the roots and twigs and other details as she got closer, as if they were thinking, 'Quick, someone's coming! Look real!' (Pratchett, 182-183)

Unlike Browning's wilderness, which irritably informs the reader it can't help how it looks, Pratchett's magical wildlife quickly tries to look realer as Tiffany inspects it, informing how Tiffany, as representative of a self-sustaining land, ${ }^{21}$ brings complication and realness with her where she goes. Similarly, the dreams and fakeness of the Elven world suggest a journey into death, as well as an ephemerality similar to that of the Fisher King's castle discussed by Nitze. In A Hat Full of Sky, there are two such abodes. The first is Tiffany's own mind, which signals her own relationship with the Chalk:

${ }^{21}$ The Queen's land is frequently described as parasitic and in The Wee Free Men is compared to a tick (183-184). 
"She tells the land whut it is, and it tells her who she is," said Awf'ly Wee Billy, tears running down his face, "I cannae write a song aboot this! I'm nae good enough!"

"Is that the big wee hag dreamin' she's the hills or the hills dreamin' they're the big wee hag?" asked Daft Wullie.

"Both, mebbe," said Rob Anybody. (235)

The second, at the climax, is the black desert of the dead, to which Tiffany takes the hiver, newly named Arthur:

Beyond the door, black sand stretched away under a sky of pale stars. There were some mountains on the distant horizon.

[...]

She took a deep breath and stepped across. (303)

Nitze's final rule regarding Fisher Kings is their participation in the Grail Ritual, specifically that of healing the land. If we regard Tiffany as a reversed Fisher King, then 'the land' or Waste in this case will be Tiffany herself. In the first book, the Waste she must heal herself of is the grief over her grandmother's death:

"I never cried for Granny because there was no need to," she said, "She has never left me!"

She leaned down, and centuries bent with her.

"The secret is not to dream," she whispered. "The secret is to wake up. Waking up is harder. I have woken up and I am real. I know where I come from and I know where I'm going. You cannot fool me any more. Or touch me. Or anything that is mine." (291) 
The healing of Granny Aching's death indicates that Tiffany has performed the Grail Ritual, as that is what heals the Waste. In A Hat Full of Sky, the Waste is the possession of the hiver. The hiver is a formless creature made up of a little bit of every consciousness it has ever possessed; whenever it possesses a person, it taps directly into their id, overriding their ego and superego. In A Hat Full of Sky, the hiver manages to possess Tiffany. This is healed through two episodes: the episode where the Nac Mac Feegle gather the items that remind Tiffany of her grandmother (more than somewhat reminiscent of a ritual, particularly as the items all evoke the idea of fecundity and agriculture), and the episode where she helps the hiver to die:

We have...understanding, said the hiver. So now we come to you with a wish. It is the wish that puts the others right.

"Yes," said Tiffany. "That's always the last wish, the third wish. It's the one that says 'Make this not have happened'."

Teach us the way to die, said the voices of the hiver. (301)

This second section is formed very like a Grail Ritual, with Tiffany asking every witch nearby, "What is the third wish?" When she gets her answer, she finally understands what it is the hiver wants, and is able to grant its wish to die. She then takes it to the dark desert of the Discworld, where the dead walk toward judgement. In doing so, she heals her Waste, and is able to understand witchcraft.

These two abodes within A Hat Full of Sky demonstrate both Tiffany's power, but also her presence as a mystical king by the rules of the Disc. As a protagonist, like all mystical kings, she is subject to change, altering over the course of her five novels. But furthermore, as a reversed Fisher King, her power is limited by the Chalk and the people on it. She is only ever as strong as the Chalk allows her to be. In A Hat Full of Sky, she finds herself unable to build a shamble, the most basic of all witch magics, until 
she finally constructs a shamble made entirely out of totemic items from her homeland. The subtext is clear: Tiffany's magic cannot work without her home clearly in her vision. The Chalk is what empowers and emboldens her. In other words, the second rule of mystical kings on the Chalk, that kings are only as powerful or helpless as their followers make them, applies to Tiffany.

The third rule of Disc monarchs is that legitimacy and purity are less important than belief. In the first book, Tiffany talks about how a strange old woman is mistaken for a witch, and how she and her house are burned and her cat killed. Three books later, in I Shall Wear Midnight, she goes to bury a stillborn child in 'the place of flowers'; a clearing in the woods where the house used to stand filled with expensive and lush flowers, and with a patch of catnip where Tiffany buried the cat, a seeming miracle:

The seeds had been expensive to buy and she had had to go all the way to Twoshirts to get them, but she had vowed that every summer the brilliance in the wood would remind people that there had been an old lady they had hounded to death and been buried here. She did not quite know why she thought that was important, but she was certain to the centre of her soul that it was. (61-62)

A legitimate miracle would be the flowers growing by magic, or as a judgement from a god, but Tiffany makes the judgement happen the hard way, because it is important to her that her people not forget a reckless error made in fear. It is not the legitimacy of the miracle that is important, but its effect that matters. This is a very Pratchettian sentiment, fitting in well alongside the Scone of Stone. When Rhys Rhysson is crowned upon it, Vimes draws a parallel between 'the thing and whole of the thing' (what the dwarfs call the Scone) and the literal act of believing (443). In fact, in Wintersmith, the concept of belief mattering more than legitimacy is even given a specific name - "Boffo" - referring to a joke company from which Witches who aren't blessed enough to already look scary get the props and tools they need to be 
frightening. It is from here Mrs Treason gets her skulls and Annagramma her makeup for her terrifying transformation, and when Tiffany confronts the Wintersmith about his inhumanness, she brings it up:

"Now, have you ever heard of boffo?"

"What is this boffo? It was not in the song!" said the Wintersmith, looking uneasy.

"Oh, boffo is how humans change the world by fooling themselves," said Tiffany. "It's wonderful. And boffo says that things have no power that humans don't put there. You can make things magical, but you can't magically make a human out of things. It's just a nail in your heart. Only a nail." (380-381)

Here, Tiffany is not discrediting the concept of legitimacy, but restating it: the Wintersmith is not human, because the essence of humanity, the ability to believe things that are not legitimate, is not a part of him. In George Bernard Shaw's play St. Joan, the Archbishop says, of miracles:

"A miracle, my friend, is an event which creates faith. That is the purpose and nature of miracles. They may seem wonderful to the people who witness them and very simple to the people who perform them. That does not matter: if they can confirm or create faith, they are a true miracle." (94-95)

In other words, the most important and delightful part of humanity is our ability to believe that which is insubstantial; these false things are made real by belief. The Wintersmith, lacking the ability to believe in miracles ("boffo") will forever be merely a snowman with a nail in his heart. 
Finally, as with Disc's many other mystical kings, Tiffany belongs, ultimately, to the Other. She mentions many times in the books that when you are a witch, you are not really a person, or a girl, or a woman to other people - you are simply a pair of hands ready to work. She loses a great many old friends, and Roland, who is her love interest for three books, ceases to be one in the fourth, due to the Feegles' 'soothings', which take away painful memories. Tiffany, when reassuring Roland's fiancée in I Shall Wear Midnight that there is nothing between the two, has this to say:

\author{
"Perhaps I should tell you," said Tiffany, "that Roland \\ and I were...well, friends. More or less the only friend \\ the other one had. But in a way, it was the wrong kind \\ of friendship. We didn't come together; things \\ happened that pushed us together. And we didn't \\ realize that. [...]. If you like, two people who were left \\ out thought they were the same kind of person.["] \\ (236)
}

As the above discussion has shown, according to the definitions provided by Nitze and Weston, it can be concluded that Wintersmith portrays the traditional story of the Fisher King, with the titular character as the Fisher King and Tiffany Aching in the role of the Questing Knight. When we deepen our perspective by adding in Pratchett's portrayal overall of mystical kings, it is easy to perceive Tiffany as a reversal of this narrative; sympathetic to her land's fecundity, and drawing power from it. Tiffany shows, perhaps, Pratchett's idealized form of what a humanist Fisher King should look like. 


\title{
Chapter 2: The Goode Childe's Booke of Faerie Tales
}

Throughout the Tiffany books, there are a great many relationships that bear striking resemblances to the famous love triangles of the Arthurian stories. When analysing these, it is important to figure out: who plays what role? What does it mean that they are cast in this role? And what is Pratchett saying from a wider viewpoint? Why take such a subversive view towards traditional Arthurian roles?

\section{The III-Made Knight}

Following the introduction of Lancelot into the Arthurian tradition after the stories were imported to France, there is a greater focus on a flawed though noble knight, who is, perhaps, less virtuous than he wishes to be. Lancelot's greatest flaw - the one that prevents him from attaining the Grail, and that, traditionally, is responsible, at least in part, for the fall of Camelot - is his adulterous relationship with Guinevere, but it's important for the modern reader to remember why his relationship with Guinevere needed to be adulterous. In The Allegory of Love, C. S. Lewis discusses how marriage and love, in the period of courtly love, were considered incompatible:

\begin{abstract}
All matches were matches of interest, and, worse still, of an interest that was continually changing. When the alliance which had answered would answer no longer, the husband's object was to get rid of the lady as quickly as possible. Marriages were frequently dissolved. [...] So far from being a natural channel for the new kind of love, marriage was rather the drab background against which that love stood out in all the contrast of its new tenderness and delicacy. (13)
\end{abstract}

This ties into Lewis' statement that one of the intrinsic properties of courtly love at this time was adultery: courtly love did not take place in the confines of marriage, for 
marriage was merely a contract, not a love match. Lancelot's relationship with Guinevere is an example of courtly love, while Guinevere's relationship with Arthur is not. In other words, the only way for Lancelot and Guinevere to love each other is in the confines of an adulterous relationship.

I mention this because, multiple times over the course of the Tiffany Aching books, characters find themselves enacting versions of the famous Arthurian love triangle. The first one starts in The Wee Free Men, where Tiffany is commanded by the dying kelda to lead the Chalk Hill Nac Mac Feegle in her absence, until the Faerie Queen can be defeated and a replacement kelda be sent for; Nac Mac Feggle are explained to have a structure like bees, with one queen and many warriors. Tiffany is fine with this at first, until she finds out what being a kelda entails:

"Guid, guid," said Rob Anybody, wiping his forehead, "So mebbe you'd like tae tell us mutter mutter mutter..."

"They want to know which one of them you're going to marry," said Fion loudly. "It's the rules. You have to choose, or quit as kelda. You have to choose yer man and name the day." (164)

Tiffany's first reaction, naturally, is panic. However, she gets around it by picking Rob Anybody, and then picking a day that will never come: when a bird sharpening its beak on the mountain at the end of the world, reduces the mountain to a grain of sand (167). Despite Fion's protests (and the Feegles' offers to wear the mountain down themselves), Rob and the others are satisfied, and Tiffany is able to lead their incursion into the Queen's realm.

Things become less clear and more awkward in the second book, A Hat Full of Sky, with the arrival of a new kelda: Jeannie from the Long Lake clan in Lancre. Despite Tiffany's marriage to Rob being a political ploy, and Jeannie and Rob loving each other very deeply, Jeannie is uncomfortable, envious, and angry at Tiffany. In other words, Tiffany has taken on the King Arthur role: her relationship with Rob, a purely contractual 
one, is a true marriage, as it would have been seen in the days of courtly romance, and Jeannie's love for Rob is the adulterous affair, hence her anger at and hatred of Tiffany. Jeannie represents a Lancelot who has fallen in love with Guinevere before being won over by Arthur. This, ironically, makes Rob, the filthy, borderline illiterate, thieving, lying Feegle, the Guinevere in this triad.

This relationship is interesting because the villain of A Hat Full of Sky is the hiver, a creature of pure consciousness, who possesses Tiffany. When it does, Tiffany's id takes control, and Rob ventures into her dreams to look after her and protect her from death (220-221). When Tiffany finally overcomes the hiver, she realizes what it is the hiver truly wants: it wishes to die (301). It's only when Tiffany is possessed and released by the hiver that Jeannie lets go of her anger and jealousy of Tiffany (331), which makes this conversation that Tiffany has with the hiver, as she shows it to the way to Death's country, all the more relevant:

["]No, you're not an 'us'. You are an 'l'."

I, me, said the hiver. I. Who am I?

"Do you want a name? That helps."

Yes. A name...

"I've always liked Arthur, as a name."

Arthur, said the hiver. I like Arthur, too. And if I am, I can stop. (305)

In other words, when Tiffany removed the hiver from her body, the hiver also took her role as the King Arthur character in this triad, symbolized by Tiffany dubbing it Arthur. It is at this point that the reader is signalled that the tension between Tiffany and Jeannie is finished, further signified when Tiffany goes to greet Jeannie after her first eight babies are born and is greeted warmly (347). Unlike Lancelot and Guinevere, Rob and Jeannie are allowed to live happily ever after.

After Tiffany gives up her role of Arthur, she takes on the role of Morgana le Fae, who is traditionally seen at the end of Arthur's story; he rests his head in her lap on the barge he takes to Avalon (Malory 717); in other words, Morgana is the one who guides 
Arthur to the underworld, just as Tiffany guides the hiver to the land of Death. Tiffany's role as Morgana is reinforced in how she wakes up from the experience:

Someone was wiping Tiffany's forehead with a damp cloth.

She lay, feeling the beautiful coolness. [...]

Tiffany opened her eyes and saw the round pink face of Petulia, screwed up with concern.

"Um, she's awake!" said the girl.

The space between Tiffany and the ceiling filled up with pointy hats. They drew back, reluctantly, as she sat up. (313-314)

Waking up, surrounded by her fellow witches-in-training, with, as is eventually revealed, her boots filled with the sand from the desert, having been gifted Granny Weatherwax's hat, all point to Tiffany's role as Morgana le Fae, who is often referred to as a witch. In this scene, Tiffany's actions lead to a revelation amongst the younger witches, and Tiffany later becomes their de facto leader in spite of the more outgoing, 'bossier' Annagramma wanting that title; in the earliest text featuring Morgana le Fae, Geoffrey of Monmouth's Vita Merlini, Morgana is noted as the ruler of Avalon and the leader of her nine sisters. ${ }^{22}$

But in her relationship with the titular elemental in Wintersmith, Tiffany is in many ways encouraged to enact the role of Nimue to his Merlin:

'Well, the poor thing hasn't quite got it right yet. He started off so well with the ice roses and everything, and then he wanted to show you his muscles. Typical.

\footnotetext{
22 "[In Avalon] nine sisters rule by a pleasing set of laws those who come to them from our country. She who is first of them is more skilled in the healing art, and excels her sisters in the beauty of her person. Morgen is her name, and she has learned what useful properties all herbs contains, so that she can cure sick bodies." (Geoffrey of Monmouth, trans. John Jay Parry, 143)
} 
But you shouldn't be frightened of him. He should be frightened of you."

"Why? Because I'm pretending to be the flower woman?"

"Because you're a girl! It's a poor lookout if a bright girl can't wind a boy around her little finger. He's smitten with you. You could make his life a misery with a word.["] (256)

In other words, Nanny Ogg is encouraging Tiffany to manipulate the Wintersmith. In most versions of the Arthurian story that involve the story of Nimue and Merlin ${ }^{23}$, Morgana, acting as a whore to Nimue's madonna, attempts to seduce Merlin for power, and is rejected. The pure Nimue enacts no seduction, but instead earns Merlin's teachings through her chastity, and eventually Merlin attempts to seduce (and in some versions, rape) her. Nimue is then forced to trick Merlin into meeting in a secluded area, where she puts an enchanted sleep on him, and then seals up the entrance, taking his place in Camelot. Wintersmith somewhat inverts this, with the Summer Lady, who only briefly meets the Wintersmith (enough for him to recognize her power, and to eventually realize that Tiffany is not her) being rejected in favour of Tiffany, who grows in power over the course of the story. Tiffany does not, however, use the mantle of summer granted to her by the Wintersmith's misstep, and instead uses a trick taught to her by Granny Weatherwax, moving heat around (33), and drawing down the heat of the sun to melt the Wintersmith and his palace and awaken the summer (382). Her relationship with him is also a lot more innocent than Nanny Ogg suggests: there is no hint of overt sexuality between them, besides a heated kiss, which seems more to represent the possibility of sexuality within Tiffany; Tiffany's grief at his banishment seems more that the world has lost, albeit briefly, something beautiful and innocent. She comments, after

\footnotetext{
${ }^{23}$ Peter H. Goodrich, in his article "The Erotic Merlin" (2000), describes the relationship between Nimue and Merlin as having been borne out of elements of earlier poems regarding Merlin's sister and wife, and eventually being described as a 'love-hate' relationship; Nimue is infatuated with Merlin because of his power and what he can give her, and loathes and fears him for his power and danger; much as Tiffany is, briefly, infatuated with the power she has over the Wintersmith, but starts to loathe him for the danger he brings to the people she loves.
} 
Summer leaves, "But him - he made me roses and icebergs and frost and never understood..." (387).

Finally, in I Shall Wear Midnight and to a certain extent in The Shepherd's Crown, Tiffany, Roland and Letitia form yet another version of the Lancelot/Guinevere/Arthur triad, though, from another perspective, it can also be seen as the Morgana/Arthur/Guinevere triad. 


\section{Tiffany's Relationships in I Shall Wear Midnight}
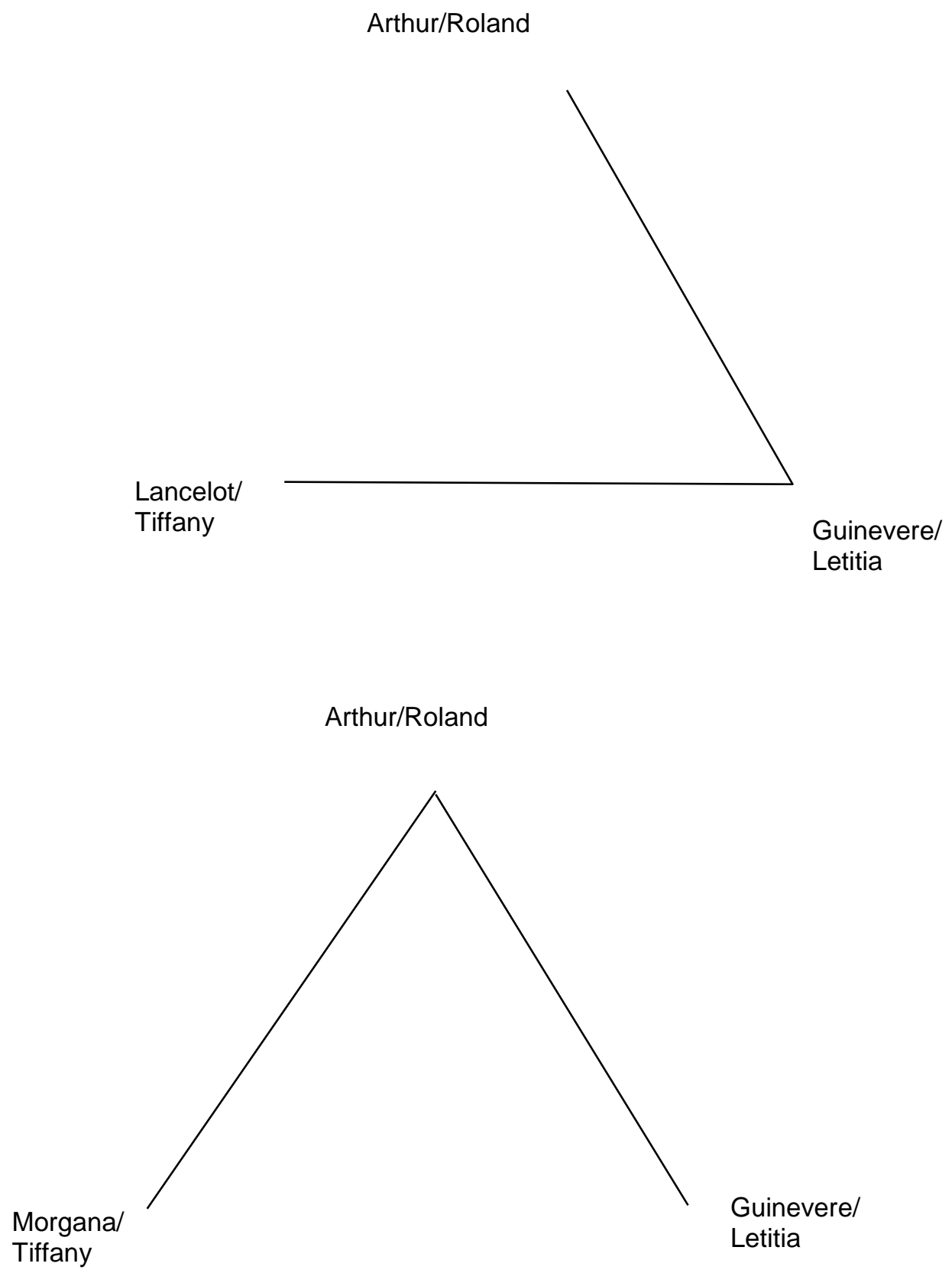
To take the Lancelot/Guinevere/Arthur triad first, Letitia Keepsake, Roland's bride-to-be, is unhappy and lonely. When Tiffany visits her in her tower (a frequent meeting place both for Tiffany and Letitia and for Lancelot and Guinevere) Letitia's nearceaseless crying comes to a halt (234), and the two start to form a fast friendship, to the point that Letitia attempts to have Tiffany as a member of her bridal party. Letitia, like Guinevere, is unwittingly the catalyst for disaster, bringing about hatred and discord upon the people of the Chalk due to a desire for love ("I didn't mean it to get that bad [...] I just wanted Roland not to like you so much["] (235).). From this perspective, Tiffany, whose blossoming friendship with Letitia allows her to put the final pieces together regarding the mystery of the Cunning Man and finally put an end to him, falls into the category of the Lancelot, and Roland, the Baron to whom she must bow, is the King Arthur. There are some notable differences, however: for instance, Letitia and Tiffany's relationship, though close, is never romantic, and although Roland attempts to assert authority over Tiffany, she never bows to his authority, and is always a step ahead of him.

In spite of this, Tiffany doesn't entirely lose her connection to the Morgana figure. At one point she comments to herself: "There is no way Roland can refuse me now. And besides, I have a secret weapon: I have the trust and confidence of a young lady who is soon going to be his wife. No man can be safe in those circumstances" (271). This connects Tiffany's Lancelot/Guinevere relationship to Tiffany's role as Morgana, who frequently attempted to manipulate the link between Lancelot and Guinevere for her own ends, for example, in Gawain and the Green Knight.

The second interpretation, that of a Morgana/Arthur/Guinevere triangle focuses on Tiffany and Roland's relationship prior to this point. They know each other as children, grow up together, and start forming a difficult and combative, but ultimately romantic relationship. At the start of I Shall Wear Midnight, Tiffany is treating Roland's father, and the reader is informed that their relationship has come to an end. Roland's father also informs Tiffany of a somewhat more meaningful aspect of Tiffany and Roland's relationship to one another: 
"I dreamed I had a visitor here last night," said the Baron, giving her a wicked little grin. "What do you think of that, then, Miss Tiffany Aching?"

"At the moment, I have no idea, sir." [...]

"It was your grandmother, Miss Tiffany Aching. She was a fine woman, and extremely handsome. Oh yes. I was rather upset when she married your grandfather, but I suppose it was for the best. I miss her, you know."

"You do?" said Tiffany.

The old man smiled. "After my dear wife passed on, she was the only person left who would dare to argue with me. [...] It is my hope, Miss Tiffany Aching, that when I am in my grave you will perform the same service to my son Roland [...] Indeed, at one point I harboured hopes that you and the boy might make a more...intimate arrangement?" (70-71)

In most Arthurian legends, Arthur's downfall is only partly due to Guinevere's adultery with Lancelot. The rest is due to the machinations of Mordred and Morgana le Fae, and the relationship between Arthur, Mordred, and Morgana is a complex one, as Linda Gowans explains in her chapter "Malory's Sources - and Arthur's Sisters Revisited" in Arthurian Literature XXIX. In the earliest text that Gowans investigates (EI Baladro del Sabio Merlin), Arthur has only two sisters; one, unnamed, becomes the wife of King Lot, who bears him multiple sons (including the treacherous Mordred), the other is named Morgain, sent to religious school and soon taking the name Morgain le Fae. As time goes on, more sisters enter the mix, bearing more of the weight of the story, until by the time Malory is writing Arthur has five half-sisters. Amy Varin, in "Mordred, King Arthur's Son", points out that the idea of Mordred as the result of an incestuous relationship between Arthur and one of his half-sisters begins in Mort le roi Artu, which predates Baladro by several hundred years. Both have elements that make their way 
into Malory, where Mordred's mother is Arthur's and Morgana's sister Morgause,${ }^{24}$ and subsequently into contemporary Arthurian literature.

The Baron's explanation of a romantic connection between himself and Granny Aching - who, as established earlier, functions as a much stronger parental figure for Tiffany than either of her parents - puts Tiffany in the position of a Morgana character to Roland's Arthur; the implicit familial connection goes along with a suggestion of romance. Tiffany also has accusations about her social status made by the unpleasant Miss Spruce:

[T]hen Miss Spruce took a deep breath [...] and screamed, "What do you think you are doing to him? Get out of here, you brazen hussy!" Tiffany's ability to speak came back quickly, and then grew into an ability to shout. "I am not brazen and I don't huss!" (78-79)

Tiffany's 'lesser' status - an unmarried woman living with her father - is a continued source of conflict in both I Shall Wear Midnight and The Shepherd's Crown, eventually pushing her toward the emotional resolution of the latter book, where she rebuilds her grandmother's shepherding hut, and officially takes over as the new Granny Aching. Furthermore, her status as a past romantic interest of Roland's is what drives Letitia to make the decisions that impact upon the plot of I Shall Wear Midnight - "I just wanted Roland not to like [Tiffany] so much" (235) she cries when explaining her actions to Tiffany. It's only when Letitia and Roland marry $(319,325)$, quietly ushering Roland as a character off the main stage, that this conflict resolves itself.

In this way, we see that, in the Arthurian love triangles, Tiffany inhabits the role of both witch and knight, and her love interests are frequently defined not by their gender roles, but by their narrative positions. Her Guineveres are a six inch tall violent

\footnotetext{
${ }^{24}$ While in Middle English literature focussing on the Arthurian, Mordred is never Morgana's child, merely her accomplice, I will refer to Tiffany's role in the love triangle as 'Morgana', as in contemporary fiction focussing on the Arthurian the two roles are often merged; and, it is in her role as a Discworld Morgana that Tiffany and Roland's romantic tension is most often brought up.
} 
Glaswegian covered in woad and a weeping would-be witch; her Arthurs her own personal id made manifest and her ex-boyfriend, a pompous Baron; her Lancelots a pregnant Feegle wife and herself.

\section{The Arthurian Other and Pratchett}

What is Pratchett's purpose in altering the genders of so many set character archetypes, and how does this affect the Arthurian narratives already set in stone? In T. S. Eliot's Arthurian magnum opus, "The Waste Land" (1922), he invites us to perceive the main character as Tiresias, the blind prophet, both male and female:

I Tiresias, though blind, throbbing between two lives,

Old man with wrinkled female breasts, can see At the violet hour, the evening hour that strives Homeward [...] (lines 218-221)

There is also the strange description of the Fisher King himself:

Who is the third who walks always beside you?

When I count there are only you and I together

But when I look ahead up the white road

There is always another one walking beside you

Gliding wrapt in a brown mantle, hooded

I do not know whether a man or a woman

- But who is that on the other side of you? (lines 359-

I quote "The Waste Land" because Eliot elegantly demonstrates that themes of queerness in gender roles have been evident in Arthurian legend for centuries: the very existence of the Fisher King, a lord symbolically or literally castrated, and restored either by the knowledge of his castration or the healing of his sword (a metaphorical penis), 
embodies Freudian notions of gender identity and transition, specifically that to embody multiple or no genders is to belong to the Other.

In looking at Pratchett's gender fluidity, the first role l'd like to analyse is that of Tiffany as Morgana le Fae. In her article "From the Lady to the Tramp: The Decline of Morgana le Fae in Arthurian Romance," Maureen Fries discusses how Morgana appears in Geoffrey Monmouth's Vita Merlini:

This initial portrayal of Morgan and her realm is a positive and even androgynous one, combining quintessentially feminine values [...] with surprisingly male-linked ones. Morgan is a teacher [...] and she rules by herself, with no sign of even a male consort over her kingdom. (2)

As mentioned previously, Morgana is linked inextricably with the fall of Camelot, so the figure Fries describes does not seem to resemble the Morgana of picture books or Le Morte D'Arthur. There's a reason for that:

Yet female counter-hero she is already in Vita, and female counter-hero she will remain as her reputation, here at its zenith, plummets from quasi-classical archetype and possible avatar of a Celtic goddess into misogynistic stereotype in the medieval Arthurian literature which is to follow. Her gradual change (one can hardly call it growth) from a connector of life with healing as mistress of Avalon, into a connector of death with illicit sex and wrongful imprisonment as she appears in most subsequent romance, indicates the increasing inability of male Arthurian authors to cope with the image of a woman in power. (2) 
Fries' argument is that in each subsequent story, Morgana's character became less and less of what she once was, until she became the wicked, inept whore who attempts to seduce Merlin to gain magical power, as Arthurian authors' egos would not allow her previous role as a goddess and leader of men, above and beyond even Merlin.

I would argue that Pratchett's returning of Tiffany to this role is a restoration: not only is Tiffany decidedly not a bad witch (unlike the distinctly morally gray Granny Weatherwax who helps teach her), she is, if not a beauty (when told the Summer Lady is 'fairer than all the stars in the sky' in Wintersmith she is encouraged to do 'something with her hair' (221) ), certainly intelligent and charming enough to get three love interests $^{25}$ and the attention of the Faerie King. Like the Morgana of Vita Merlini, she is associated with Earth Motherly fertility: her sympathetic link to the Chalk means as a young girl she is empowered by its fecundity and strength, and while there's no mention of the plough (which Fries calls 'male-associated' (2) ), it is sheep and goat farm land, as well as cornfield land. The only hint of male dominated industry to come upon it train track - will happen long after the end of the final book. Like Morgana, Tiffany can fly, and although not shapeshift, she can Borrow, or place her mind into that of another animal. And, like Morgana, Tiffany is a healer and a teacher.

Pratchett's decision to place Tiffany in a Morgana role but to remove, in many ways, the negative connotations of that role, as well as restoring all the positive ones, suggests a feminist perspective: a rejection of the whore Morgana and all of the intrinsic patriarchal notions that made her that way.

However, Pratchett takes it a step further than that, by also placing women in traditionally masculine roles and vice versa. He even goes one step further, and has the men who do take on the masculine work succeed due to a rejection of their masculinity and an embrace of the traits usually deemed feminine: imagination, creativity, intelligence and a lack of physical prowess. In order to understand Pratchett here, first I want to examine possible reasons for why women and men are delineated in the way they are.

\footnotetext{
${ }^{25}$ Four if you count the Cunning Man in I Shall Wear Midnight, who is described as mistaking her for the talented and beautiful witch responsible for his burning, hundreds of years in the past.
} 
In Shelly Ortner's anthropological article "Is Female to Male as Nature is to Culture?" she examines possible reasons as to why, in every known culture, women are always treated as the subservient, and men as the superior. This is the conclusion she comes to:

What could there be in the generalized structure and conditions of existence, common to every culture, that would lead every culture to devalue women? Specifically, my thesis is that woman is being identified with, or, if you will, seems to be a symbol of, something that every culture devalues, something that every culture defines as being at a lower order of existence than itself. Now it seems that there is only one thing that would fit that category and that is "nature" in the most generalized sense. Every culture, or, generically, "culture" is engaged in the process of generating and sustaining systems of meaningful forms (symbols, artifacts, etc.) by means of which humanity transcends the givens of natural existence, bends them to its purposes, controls them in its interest. We may thus equate culture broadly with the notion of human consciousness, or with the products of human consciousness [...] by means of which humanity attempts to rise above and assert control, however minimally, over nature.

In other words, women are seen as subservient to men because women are seen as similar to nature, or rather, the idea of "nature" - that is, raw materials from which to construct "culture", the masculine concept of reality.

If we stay within the confines of Ortner's metaphor and examine Tiffany, Tiffany exists as both nature and culture. As the living sympathetic embodiment of the Chalk, 
and as a growing young woman, she is inherently tied into nature. As a witch, able to ride along the minds of tiny animals, she is bound to nature, forever. However, as a shepherdess and a dairymaid, she is forever bending nature to her will to create culture; she asserts dominance over Miss Level's herd of goats. And then there is this expository moment that Rob Anybody gives whilst in Tiffany's dream of the chalk in $A$ Hat Full of Sky:

Rob Anybody stared at it. It had to mean something. He watched it carefully. Little bush, growing... And then he remembered something the old kelda had told them when he'd been a wee boy. Once the land had been all forest, heavy and dark. Then men came and cut down trees. They let the sun in. The grass grew up in the clearings. The bigjobs brought in sheep, which ate the grass, and also what grew in the grass: tree seedlings. And so the dark forests died. There hadn't been much life in them, not once the tree trunks closed in behind you; it had been dark as the bottom of the sea in there, the leaves far above keeping out the light. [...] Deep inside the forest, the everlasting forest, was the home of wood. But the turf lived in the sun, with its hundreds of grasses and flowers and birds and insects. The Nac Mac Feegle knew better than most, being so much closer to it. What looked like a green desert at a distance was a tiny, thriving, roaring jungle... (223)

In other words, Pratchett is providing an alternative to Ortner's argument that destruction of nature feeds into creation of culture and therefore that oppression of women feeds into dominance of men. Pratchett is putting forward the idea that destruction of nature can sometimes feed into a cycle of culture and nature living 
together harmoniously, as they do in Tiffany Aching. Consider the Shepherd's Crown that she acquires near the end of the series: it was created by the death of nature, but also a fossil: it can only be created by nature. In order to wear it, Tiffany makes a leather thong for it to wear around her neck. Consider her other necklaces: the horse and the hare. Both represent challenges she faces, and both also represent natural phenomena (the hare and the chalk beneath the turf). They also represent the folklore surrounding those phenomena (the folklore of the hare running into the fire; the chalk pictures drawn for the gods).

By presenting nature and culture as a harmonious living synthesis, Pratchett is also able to present masculine and feminine traits as working harmoniously together. Roland wishes to be an excellent swordsman, but isn't: however, his ability to read and his imagination are, in the end, what save him in the Underworld and what earn his respect from the Feegles in Wintersmith (377-378). The Baron dies, not fighting gloriously, but weeping nostalgically for a day with his father, watching the stubble burn and singing "The Larks They Sang Melodious" in I Shall Wear Midnight (79-80). In that same book Preston, Tiffany's eventual beau, woos her not with strength but with his intelligence and extensive vocabulary (204).

This complication with the gender binary continues even in the female characters: Magrat Garlick, always called a 'wet hen', who excels in medicines, wears armour to battle Elves and famously shoots one with a crossbow through a keyhole (Lords and Ladies 234); Angua from the City Watch books has a long romance with Captain Carrot, but is also animalistically vicious and prone to bouts of hairiness due to her lycanthropy; and so on. We must also keep in mind that our perception of which character traits are perceived as masculine and which as feminine may differ from how they are presented. Smoking a pipe and drinking a beer may be perceived as masculine, but fit into the feminine caricature of the cheerful old English Granny that Nanny Ogg is playing off. Power, no matter the source, is frequently perceived as masculine, but in the Discworld, power exists outside of gender, so Granny Weatherwax's ability to strike fear into the heart of dwarfs, trolls and even Death is neither masculine nor feminine; it is not nature, or culture, it merely is. This ability to portray outside the gender binary allows Pratchett more mobility in his character 
development and in the kinds of stories he is able to tell, as well as the kinds of story arcs his characters can go through.

Pratchett's presentation of female and male traits in his characters means that having characters in Arthurian roles outside of their genders is merely an extension of this harmony. It also means a reexamination of what those stories mean, particularly being retold in a new time and place. Fries writes of the roles belonging to female Arthurian characters:

$[T]$ hese roles include the heroine, the female hero and the female counter-hero. Heroines are essentially passive figures [...] who know and guide the hero to his destiny [...]. Arthurian female heroes, contrariwise, exist (at least for a time) as active helpers to male heroes, but always in the service of the patriarchal culture the hero upholds [...]. Possessing the hero's superior power of action but not his adherence to or ability to renew the values of the dominant culture, the counter-hero violates the norms of the Arthurian patriarchy in some way - for males, usually by wrongful force and/or denial of mercy, and for females, by the greater or lesser magics and/or sexual seduction, sometimes leading to destruction. (2-3).

None of Pratchett's main characters, particularly in the Tiffany Aching series, really fall into the role of the passive heroine, and Pratchett admitted a difficulty in writing what he called 'soft' women. The closest we perhaps get is Petulia, whom Tiffany admits has a core of iron to her in A Hat Full of Sky:

She had a momentary picture of Petulia standing in front of some horrible raging thing, but it wasn't as 
funny as she'd first thought. Petulia would stand in front of it, shaking with terror, her useless amulets clattering, scared almost out of her mind...but not backing away. She'd thought there might be people facing something horrible up here, and she'd come anyway. (279)

Arthurian female heroes (who possess agency, but only to reinforce patriarchal values), as Fries describes, are also few in number, both in the Tiffany Aching novels and in the wider Discworld. To the extent such heroines exist, they are inevitably commentaries on specific patriarchal trends, turn out to be much deeper than they first appeared, or are jokes at the expense of the heroes they support (examples include the Baroness Keepsake, Amber Petty and, for a time at least, Letitia Keepsake).

Fries' definition of the counter-hero, however, is worthy of some pause. It is how she defines the original depiction of Morgana, and it also helps us to define most of the Arthurian depictions found in the Tiffany Aching books. The Feegles, for instance, frequently show a total lack of mercy, especially when their home is at risk. Take this scene from I Shall Wear Midnight when the Baron's guards are threatening to dig up their mound:

"Listen to me, Rob," Tiffany began, but stopped. Rob Anybody's face was dripping tears, and he was pulling desperately at his beard as he fought the horrors of his imagination. They were an inch from a war, Tiffany reckoned.

'Rob Anybody! I am the hag o' the hills and I put an oath on you not to kill these men until I tell you to! Understand?"

[...]

The Big Man of the Feegles hesitated as his spinning brain digested Tiffany's order. True, it wasn't an order 
to kill anybody right now, but at least it held out the possibility that he might be able to do so very soon, so he could free his head from the terrible pictures in his mind. (181)

Wee Mad Arthur, the newest Feegle, later calls the attack upon the Feegle home "the sin o' sins" (270).

As for Fries' definition of a female counter-hero, while there are many female magic users (the vast majority of the major characters in the Tiffany Aching series are Witches), the only characters who really perform anything like 'seductions' are Nanny Ogg in her youth, and, perhaps, Nightshade, as the Queen of Fairies. While Tiffany is encouraged to try this with the Wintersmith, she rejects her sexuality for most of the book series; while aware of where babies come from, she doesn't really want anything to do with it. In many ways, her roles fit far better with the male counter-hero, as she violates Roland's heteronormative ideals of how power and strength should function, frequently rescuing him.

This ability of the protagonists - to have both the female counter-hero's magic and the male counter-hero's ability to violently violate patriarchal standards - again helps to cement my argument that Pratchett is dealing his characters a gender-balanced deck of traits, complete with gender-switching their roles; in the Disc, where the Story or Narrativium will take anyone who appears to fit, the Story must go on, regardless of how bad a fit it is. In other words, Pratchett is more interested in the power of story on its participants, regardless of the gender of those participants. This is true both in the stories (where Tiffany is brutally forced into enacting the Summer Lady's role, complete with Fertile Feet and a Cornucopia, because of the story working upon her) and the narration (in The Shepherd's Crown the text presents the mystery of who will inherit Granny Weatherwax's steading in an Arthurian manner, with characters who have never met either Granny or Tiffany reacting to the news of Tiffany's appointment as if it is the most important change in the world (60,65-69)).

A switch in gender for the Arthurian roles replaces Lancelot's devotion to Arthur with Jeannie's jealousy and duty in spite of her anger and wrath; it replaces Lancelot's 
adoration and love of Guinevere with Tiffany's hesitant friendship and eventual affection; it replaces Arthur's cool contract with Guinevere with Tiffany's amusing 'getout-of-jail-free' card escapade and Roland's sincere admiration; and it replaces Guinevere's deception with Letitia's fear and Rob's loyalty. The stories remain the same, but the emotional notes change, sometimes drastically.

While in the Arthurian tales, as demonstrated by T. S. Eliot, the genderqueer exists to indicate something alien, magical, or Other (as, for example, the cases of Tiresias, the Fisher King, and Morgana), Pratchett allows all of his characters something of the queer, just as most of them are allowed something of the Other. Pratchett's encouragement of the Other amongst his cast may be seen as a strange move, but I argue that it is, in fact, Pratchett's rejection of a binaried story. By casting the Arthurian roles this way, Pratchett is implying that the world is not a binary, but a spectrum. The best example of this comes in The Shepherd's Crown, in the form of Geoffrey, the boy who wants to be a witch.

Geoffrey is an almost perfect exemplar of the Galahad ideal: he is noble, good, kind, and although religion is never discussed very strongly in the Tiffany Aching books, there is a strong sense of spirituality to him. He is a vegetarian Calm-Weaver, a uniquely masculine trait that allows him to undo the pain of toxic masculinity in the men around him. He is described as supernaturally likeable, on the scale of Captain Carrot (possibly even beyond him). Despite being described as gentle, however, in the book's climax, he leads a group of disenfranchised engineers to battle against the toxic influence of the Elves (296-301), who he loathes for being like his father, who smeared his face with a vixen's blood after he refused to hunt (30). He has both positive masculine and feminine traits, definitely marking him as part of the Arthurian Other, but he is one of the heroes of Pratchett's tale.

\section{First Sight and Second Thoughts}

When Tiffany is asked by Miss Tick in The Wee Free Men why she wants to become a witch, she immediately starts thinking of the book of fairy tales her mother read to her as a child: 
If it came to that, the book never gave you evidence of anything. It talked about 'a handsome prince'....was he really, or was it just because he was a prince that people called him handsome? As for 'a girl who was as beautiful as the day was long'...well, which day? In midwinter it hardly ever got light! The stories didn't want you to think, they just wanted you to believe what you were told... (37)

This is one of the first hints of Pratchett's subversive nature in the Tiffany Aching books. In a way, the manner in which he casts his love triangles can all be seen as an extension of his distaste for and rebellion against traditional stories and what they promote: an inability to think for oneself, and a tendency to view reality in stories which Pratchett then displays in a story.

While Pratchett's heroine finds herself frequently at the mercy of stories, she is also frequently at the mercy of stories with no comfortable or satisfying resolutions, unlike the fairy tales she reads at the beginning of The Wee Free Men. In A Hat Full of Sky, while possessed by the hiver, she steals the life savings of the elderly Mr. Weavall, a box of bronze and silver coins, kept to pay for his eventual funeral (112). When she goes back, she finds that her Feegle friends have stuffed the box previously containing his life savings to the brim with gold coins (261). After she tells him what has happened, he thanks her and pays her to help get him dressed because "[T]his is far too much money to buy a man's funeral, but I reckon it'll do fine to marry him off" (263). This leads to this conversation:

"Well," said Mistress Weatherwax as, with jacket flying, he rounded the corner. "That was nice, wasn't it?" 
"Er, yes," said Tiffany, taking out a handkerchief and blowing her nose.

"But it worries you," said the witch, "You think it shouldn't have ended like that, right?"

"No!" said Tiffany hotly.

"It would have been better if he'd been buried in some ol' cheap coffin paid for by the village, you think?"

"No!" Tiffany twisted up her fingers. [...] "But...all right, it just doesn't seem...fair. I mean, I wish the Feegles hadn't done that. I'm sure I could have...sorted it out somehow, saved up..."

"It's an unfair world, child. Be glad you have friends." (266)

While Mr Weavall's story has a happy ending in spite of Tiffany's (and probably the reader's) discomfort, there are other stories Pratchett depicts, far closer to reality, with no comfortable ending.

I Shall Wear Midnight opens with the rough music, slang for a mob, coming for Mr Petty after he beats his pregnant teenage daughter Amber so hard that she miscarries (30). Tiffany tells Mr Petty to get going and takes Amber to be healed by Jeannie, only to find Mr Petty later having attempted suicide after wrapping the miscarried infant in a funeral shroud and making a bouquet of nettles for it (57). ${ }^{26}$

After Tiffany rescues Mr Petty from his attempted suicide, he isn't seen until near the end of the book, at the Baron's funeral, where he and Tiffany are wordless (286). Perhaps, in a more comfortable, less realistic story, Mrs Petty would have left him; Mr Petty would have displayed repentance in a way visible to the community, rather than one lone woman in the dark; but the lack of closure to the story of the Pettys, other than to note the joy of Amber and later, that of her husband, and her deep talent and where it may take her one day, is true to life: too often, our villains do not get the ends they

\footnotetext{
${ }^{26}$ Tiffany notes one thing that irritates her about the Pettys is how their house only has nettles growing in the garden, a metaphor for family discord.
} 
deserve. Pratchett's refusal to have a bitter end come to Mr Petty, or a catharsis other than his mute acknowledgement of what he's done, are not perfect stories in the way that Tiffany banishing Winter for the oncoming Summer is; but they do allow us to review what it means to narrativise reality.

If there is one ongoing theme in Pratchett's Tiffany Aching series, it is a distaste for the narrativisation of reality. Narratives, we are told, are useful tools, but they should not replace reality, as we're informed in I Shall Wear Midnight:

"You are a witch." The words came out of Tiffany's mouth all by themselves, unable to stay in the privacy of her mind.

[Letitia] looked at her in astonishment. "Don't be silly," she said. "We both know how it goes, don't we? Long blonde hair, milk-white skin, noble - well a reasonably noble birth - and rich, at least technically. I'm officially a lady."

"You know," said Tiffany, "maybe it's wrong to base one's future on a book of fairy stories. Normally girls of the princess persuasion don't help out distressed headless ghosts by giving them a pumpkin to carry.["] (244)

It is better - and easier - to accept that sometimes reality does not match our expectations as taught to us by the narratives we consume in our childhood, than to continuously try to enforce these narratives onto reality.

This may be part of why Pratchett chooses to swap the genders on his Arthurian love triangles: to teach us that reality (and narratives) need not conform to narrative expectation, regardless of our own formalized prejudices and bias regarding narratorial reality. The Lancelot role can also be filled by a Morgana character; the Guinevere can also be a male fighter. Nothing prevents either of these from being true except for 
preconceived notions of how these stories should be told. This is where Tiffany's witchly powers of 'First Sight' and 'Second Thoughts' come from:

\begin{abstract}
"Ye have the First Sight and the Second Thoughts, just like yer granny. That's rare in a bigjob."

"Don't you mean second sight?" Tiffany queried. "Like people who can see ghosts and stuff?" "Ach, no. That's typical bigjob thinking. First Sight is when you see what's really there, not what your heid tells you ought to be there. [...] Second sight is dull sight, it's seeing only what you expect to see." (140)
\end{abstract}

Second Thoughts are later explained as Tiffany thinking about how she is thinking; she even has Third and Fourth Thoughts, though she isn't quite sure if she's meant to have the Fourth Thoughts.

First Sight can be defined as viewing reality through a prism of subversive narrative; it acknowledges the narratives surrounding the viewer, whilst rejecting the vast majority. The best example comes later in The Wee Free Men:

She glanced around, and there was the drome. It was almost hidden behind a pillar.

Roland just stared at her.

"Are you all right?" said Tiffany desperately, trying to shake him. "Have you eaten anything?"

"Fwa fwa faff," murmured the boy.

Tiffany turned back to the drome. It was moving towards her, but very slowly, trying to stay in the shadows. It looked like a little snowman made of dirty snow.

[...]

"First Sight," breathed Tiffany. 
In this sequence, Tiffany is caught in a dream, spun by the dream-spinners, the dromes. If you eat dream-food, you become trapped in the dreams; however, removing the head of the drome finishes the dream (192-193). But dromes have difficulty replicating human speech (just as, in a dream, speech is difficult to hear) (212). Tiffany understands that the drome spinning this dream panics, spinning a dream where Roland is disguised as the drome, because First Sight shows her reality, rather than the convenient story. The sequence has a great deal in common with the peach sequence from Jim Henson's movie Labyrinth, in which Sarah dreams of a ball with David Bowie's Jareth. Tiffany, however, chooses to confront and behead her Jareth rather than flee him.

Conveniently, it also falls into line with the fairytale The Wee Free Men most closely resembles: Childe Rowland, a tale in which Rowland's siblings are, due to his sister Burd Ellen going widdershins around a church, kidnapped by the fairies. Rowland is instructed to eat no food and to behead all who try to speak to him until he encounters his siblings. ${ }^{27}$ Again, Pratchett plays with narratorial convention; Roland is one of the captured people whom Tiffany must rescue, and when she succeeds, credit for the rescue is given entirely to Roland, to Tiffany's initial frustration, though she eventually moves past it, and uses it as a device to establish their further relationship:

"I did try [to tell the truth]," said Roland. "Honestly. I really did."

I expect you did, Tiffany thought. But you're not very clever and the Baron certainly is a man without First Sight. He sees the world the way he wants to see it. "One day you'll be Baron, won't you?" she said. "Well, yes. But look, are you really a witch?"

\footnotetext{
${ }^{27}$ Childe Rowland also contains the use of the word 'bogle', the name of the monsters Roland fights when he enters the Underworld in Wintersmith. In the poem, Rowland beats the Fairie King to his knees, upon which point he releases his brothers and sister, similar to how Tiffany slaps the Queen of Fairies to the ground.
} 
"When you're Baron you'll be good at it, I expect?" said Tiffany, turning the butter around. [...]

"Well, I hope I -"

Tiffany turned to face him, a butter paddle in each hand.

"Because I'll be there, you see. You'll look up and see my eye on you. l'll be there on the edge of the crowd. All the time. I'll be watching everything, because I come from a long line of Aching people and this is my land.["] (314)

See again, the reference to First Thoughts; the Baron's lack of First Thoughts means that he views the reality of the novel through a specific type of narrative lens. Three books later, in I Shall Wear Midnight, the Baron reveals that Tiffany's father has told him her side of the story, and asks for the truth, which Tiffany gives:

"And why didn't anybody tell me this at the time, pray?" said the Baron.

"Because you are the Baron," said Tiffany, simply, "and boys with swords rescue girls. That's how the stories go. That's how stories work. No one really wanted to think the other way round."

"Didn't you mind?" [...]

"Yes," she said, "A bit."

"Was it a reasonably large bit?"

"I would say so, yes. But then I went off to learn how to be a witch, and it didn't seem to matter any more.["] (73)

The Baron then rewards Tiffany for the rescue of his son and "removing another lie from the world" (76). It becomes clear that, as difficult as it may seem, it is indeed 
possible for people to see beyond Second Sight; to see the truth of the matter, if they are provided with it and wish to see. First Sight may force truth and reality upon people, but there is nothing stopping people choosing to see that truth, aside from the stories we tell, again and again.

The concept of seeing what we expect to see becomes complicated in Wintersmith with the character of Miss Treason, a 113-year old witch who is much mythologised:

Then there was her clock. It was heavy and made of rusty iron by someone who was more blacksmith than watchmaker, which was why it went clonk-clank instead of tick-tock. [...]

There was a story in the villages that the clock was Miss Treason's heart, which she'd used ever since her first heart died. But there were lots of stories about Miss Treason.

[...]

People would come from miles around to bring her their problems:

I know it's my cow but he says it's his!

She says it's her land but my father left it to me!

...and Miss Treason would sit at the click-clacking loom with her back to the room full of anxious people.

\section{[...]}

And then, when all the words had been said, the loom would stop with a shock of sudden silence, and Miss Treason would turn around in her big heavy chair, which had wheels on it, and remove the black blindfold from her pearly grey eyes and say:

"I have heard. Now I shall see. I shall see what is true." (39, 41-43) 
The many stories of Miss Treason are gone into great detail over the early parts of the book, from the demon supposedly in her cellar (44) to her apparent immortality (120-121), to her slicing people up with her thumbnail (87). However, Tiffany discovers her secret when she knocks over one of her two skulls and finds that a lot of what makes her frightening is bought from the Boffo Joke Shop in Ankh-Morpork (88). In fact, most of the mythology comes straight from Miss Treason herself:

"You made up stories about yourself?"

"Oh, yes. Of course. Why not? I couldn't leave something as important as that to amateurs."

"But people say you can see a man's soul!"

Miss Treason chuckled. “Yes. Didn't make that one up! But l'll tell you, for some of my parishioners l'd need a magnifying glass! I see what they see, I hear with their ears. I knew their fathers and grandfathers and great-grandfathers. I know the rumours and the secrets and the stories and the truths. And I am Justice to them, and I am fair. Look at me. See me."

Tiffany looked - and looked past the black cloak and the skulls and the rubber cobwebs and the black flowers and the blindfold and the stories, and saw a little half-deaf blind old lady. (89)

Miss Treason survives as a witch due to people's lack of First Sight, their inability to see the truth of her condition: that she is as vulnerable as any old lady, but that it is the stories surrounding her, the narratives and metonymy of justice, that give her power. Without those mythologies, Miss Treason would suffer deeply, just as, in the first novel, Mrs. Snapperly suffers, driving Tiffany to becoming a witch. ${ }^{28}$ In this way, Pratchett

\footnotetext{
28 "Tell me why you still want to be a witch, bearing in mind what happened to Mrs Snapperly?"
} "So that sort of thing doesn't happen again," said Tiffany. (The Wee Free Men, 48) 
complicates the matter of his subversive attitude toward stories, by highlighting the ways in which complicity with narrative is sometimes the only way in which women, particularly vulnerable women, are able to remain safe. Annagramma also has to buy into this when she takes over Miss Treason's job near the end of Wintersmith (316), and it is the only way for Tiffany, for most of the novel, to remain protected from the Wintersmith's advances. By complicating this stance, Pratchett reinforces the readers' complicity in applying these narratives onto reality in harmful and hypocritical manners, especially regarding women. Tiffany's comment to Letitia regarding hair color in fairy tales still stands: how frequently are female characters' hair colours used as shorthand for their intelligence and personality?

This complication extends into the nature/culture debate: masculine culture obscures the true nature of things, which witches, through the auspices of First Sight, are able to reveal. But witches thrive on respect; in order to attain respect, both in the masculine and feminine sphere, they must occasionally cannibalize their own reputations to attain respect in the masculine sphere..

And what of Second Thoughts? Second Thoughts (and any thoughts coming after that) are the nature of critical analysis, considering what the witch is thinking and why. Consider this sequence from Wintersmith:

The hand stopped about a foot away from her. It formed into a fist, and now it turned over and the fingers opened.

Something gleamed. It was the white horse, made of silver, on a fine silver chain.

[...]

Her First Thought was: Take it.

Her Second Thought was: Don't take it. It's a trap.

Her Third Thought was: Really don't take it. It will be colder than you can imagine. (80-81) 
With each thought, we see her getting less emotional and more analytical. Her First Thoughts are the most emotional, the most sentimental; while her Second Thoughts are more analytical, there is still a place for distrust and fear. Her Third Thoughts are the most analytical of all, pointing out the risk of touching something metal held in a hand composed of snow. This is even pointed out on the same page:

That's interesting, said her Third Thoughts, that busied themselves with the world in their own way. You can't see what's hidden inside an invisible fist. How does that work? And why are those little purplegrey blurs in the air where you'd expect to find eyes? Why aren't they invisible?

That's Third Thoughts for you. When a huge rock is going to land on your head, they're the thoughts that think: Is that an igneous rock, such as granite, or is it sandstone? (81)

Tiffany's ability to perceive reality beyond the veil of narrative, and her ability to observe unemotionally, are both not only stereotypically masculine traits, but they also mark a rejection of typical narrative convention. Tiffany's power is the power to recognize and, where necessary, subvert narrative:

"What is it you want?" said the Summer Lady. [...]

"Want?" said Tiffany. "Nothing. Just the summer, thank you."

The Summer Lady looked puzzled. "But humans always want something from gods."

"But witches don't accept payment. Green grass and blue skies will do." (385) 
By presenting a subversive reaction to narratives, Pratchett also presents a subversive reaction to gender within those narratives and to the tropes that make up those gender expectations and gender roles. This, then, is his purpose in allowing characters to take character roles in romances that are opposed to their gender: to prove the point that narrative and reality are, at the end of the day, incompatible. Because no reality ends comfortably. 


\section{Chapter 3: Cracked Mirrors and Melting Girls}

In Pratchett's Tiffany Aching books, there is no more obvious an intertextual reference to the Arthurian than Letitia Keepsake in I Shall Wear Midnight, who as a whole constitutes a reference to or parody of Tennyson's "The Lady of Shalott", first published in 1832, then revised in $1842 .{ }^{29}$ In this chapter, I will discuss the Lady's heritage as part of the Arthurian tradition of 'ladies in towers,' the critical analysis of the Lady as an artist in the tower, and do a close reading of "Lady of Shalott" in the context of light and shadow with an eye to applying this reading to Letitia as she is depicted in I Shall Wear Midnight.

\section{Tennyson's Inspiration}

Up in her tower, away from the world, Tennyson's Lady of Shalott is condemned to view the world only through a magic mirror, and to never see the world as it truly is. When she views Lancelot's face in the mirror, she gives in to temptation and crosses the room and looks through a window, causing the curse to enact itself upon her, resulting in her death:

She left the web, she left the loom

She made three paces thro' the room

She saw the water-lily bloom,

She saw the helmet and the plume,

She look'd down to Camelot.

Out flew the web and floated wide;

The mirror crack'd from side to side;

'The curse is come upon me,' cried

The Lady of Shalott. $(109-117,1842)$

\footnotetext{
${ }^{29}$ While the 1842 version is the author-preferred text, for most of this chapter I will refer to the 1832 version, for reasons that will be explained.
} 
The Lady of Shalott, in many ways, acts as the ultimate figurehead of the tradition of the Lady in the Tower, indicating all of the proper character archetypes: she is beautiful, artistic, trapped, lonely, romantic. There is something otherworldly about her (she is described in the text as a 'fairy'). When she sees the beautiful Lancelot riding by, his goodness and handsome demeanor immediately invite her curiosity; in a manner of speaking, her infatuation is what brings the curse upon her (as the love of the characters who have come before her brings their downfall and ruin). The manner of her death is chosen by the author to be beautiful and evocative of both helplessness and suicide; she, as the famous quote goes, dies young and leaves a pretty corpse ${ }^{30}$. And as it is for many of the women in these stories, that is all that is known of her: her beautiful, flower-strewn corpse.

I would like to examine more closely the heritage from which Tennyson has drawn "The Lady of Shalott" - the artist in the tower, and more specifically, 'the-lady-inthe-tower" what Maureen Fries calls the 'Arthurian heroine, ${ }^{31}$ :

Heroines are essentially passive figures, not knowers but [...] 'what can be known', who lure and guide the hero to his destiny with their prime virtue of beauty being poised for their prime function of love object and/or wife.(2)

In fairy tales, these are often figures who have breached societal convention of some kind; or, more frequently, their family has breached social convention and they bear the punishment. Examples include Rapunzel, the unnamed heroine of Rumpelstiltskin, Beauty from Beauty and the Beast, and Aurora from Sleeping Beauty. In Arthurian tradition, the tower serves both as a prison for women who act in opposition to societal convention, and as a protection: within the confines of the tower, the women within this tradition are safe. It is frequently when the women leave the tower

\footnotetext{
${ }^{30}$ The full quote "Live fast, die young, leave a pretty corpse" has been attributed to many people over the years, leaving proper attribution impossible.

${ }^{31}$ Further discussion of Fries' definitions and categorization of Arthurian female figures can be found in this thesis on pages 66 and 70-73.
} 
that their tragic ends are inflicted upon them. The tower is specifically reserved for heroines who breach societal conventions - female counter-heroes, those who reject societal conventions and are often cast as villains, rarely end up in towers.

While Guinevere, Arthur's wife and Lancelot's lady love, is not a typical example of this type of character, she is intrinsically linked to many aspects of their stories: her rejection of society's mores via her affair with Lancelot, her continued punishment via the men who are meant to serve as her protection through their accusations of her villainy, and her final fate, which is to become a nun, removed from both the world and the narrative entirely:

I truste, thorow Goddis grace and thorow Hys Passion of Hys woundis wyde, that aftir my deth I may have a syght of hys blyss[ed] face of Cryste Jesu, and on Doomesday to sytte on Hys ryght syde; [fo]r as synfull as ever I was, now ar seyntes in hevyn. [...] And I commaunde the, on Goddis behalff, that thou forsake my company. (Malory 720)

Her dismissal of her love after her near-burning, the death of her husband, and the end of Camelot's golden age, as well as her giving herself over to God, is a move that could be dismissed as a sudden swerve ${ }^{32}$, but one that also makes perfect sense for a woman continually at the mercy of men who should be her protectors but who have instead turned on her or failed to protect her. These aspects of Guinevere's story tie into one of the major themes of the Lady in the Tower: the tragedy of their conditions, and their inevitable ends, either as dead or as nuns and therefore uninvolved with the narrative (so, narratively speaking, dead).

\footnotetext{
32 "Are we to be pleased that [Guinevere] is reformed, arguably, remade as a devout Christian? If so, that does not seem encouraged or reflected in the mood set by the text. Her righteousness seems out of place in the face of Lancelot's passion. She even suggests that he needs to return to his worldly ways, so little faith does she have in either his dedication or his love." (Sweeney 75)
} 
The first in the tradition proper is Elaine of Carbonek, Galahad's mother and King Pellem's daughter. When Lancelot first comes to Carbonek, he encounters a girl ${ }^{33}$ trapped in a scalding bath. After he rescues her, Elaine falls in love with him, and tricks him into mistaking her for Guinevere, resulting in the birth of Galahad (Malory, 478-481). Elaine is able to stay Lancelot's wrath, but a later event in which Elaine tricks Lancelot results in Guinevere's jealousy and Lancelot's madness during which he becomes Le Chevalier Mal Fet, cured only by the presence of the Grail $(487,503)$. Her entrapment within Carbonek Castle and her unrequited love for Lancelot (which results in the birth of Sir Galahad the Pure) are the character aspects which feed into Tennyson's "Lady of Shalott".

The Fair Maid of Astolat appears both in Malory's work and in Tennyson's Idylls of the King. Malory depicts her as a beauty that Lancelot spurns, causing her suicide; it is in death that her love letter to him is read, and she is buried with full honours (Malory, 631-641). The implication, that for a woman unrequited love is such a burden that it can only be cured with death, is an unpleasant one. Tennyson gives a similar story, though the Fair Maid's death, instead of causing Lancelot to bury her with honours, instead causes Lancelot such grief that he throws himself beside the river and recounts his guilt:

For what am I? what profits me my name

Of greatest knight? I fought for it, and have it:

Pleasure to have it, none; to lose it, pain;

Now grown a part of me: but what use in it?

To make men worse by making my sin known?

Or sin seem less, the sinner seeming great?

Alas for Arthur's greatest knight, a man

Not after Arthur's heart! (sec. 8, par. 75)

\footnotetext{
${ }^{33}$ There is much disagreement among Arthurian authors as to whether the girl in the bath is Elaine of
} Carbonek herself; T. H. White casts her as the girl in bath, but Malory does not. 
Instead of implying that unrequited love causes women unbearable pain, Tennyson's implication here is that it causes the man unbearable pain as well as possibly unwarranted guilt.

Tennyson's poem "The Lady of Shalott" is based on the tale of the Fair Maid of Astolat. However, where the Fair Maid's story is intended to throw further light on the relationship between Guinevere and Lancelot, "The Lady of Shalott" is a self-contained story set completely apart, and featuring only the Lady and Lancelot as named characters. Because of her isolation relative to other characters, one of the most common and contested critical readings of "The Lady of Shalott" is that of the artist in the tower: the concept that the Lady represents the allegorical ideal of the artist as separate from reality, with the cursed mirror representing how an artist does or should see reality, and her weaving as the art. The artist in the tower is such a common interpretation that it is helpful to explore critical interpretations of it over the years.

\section{The Artist in the Tower}

That "The Lady of Shalott" represents the artist in the tower is a reading that has been discussed for at least seventy years. It is a layered, complicated argument, with many components involved. Critically, there is a great deal of discussion over to what extent the artist the Lady represents is also Tennyson, and whether her death represents, allegorically speaking, a happy ending.

In Lionel Stevenson's analysis ${ }^{34}$ of Tennyson's frequent use of the imagery of the damsel, he writes of the character of the Lady:

The lady of Shalott is an artist, weaving beautiful pictures which are supposed to reproduce real life but which are derived entirely second hand through the mirror. At the beginning of the poem she is entirely happy with her artificial, lifeless creations. When she

\footnotetext{
34 The 'High-Born Maiden' Symbol in Tennyson." PMLA. Vol. 63, no. 1, Mar. 1948, pp. 234-243. Web. 14 Nov. 2017.
} 
first catches a glimpse of real emotion, even in the mirror (the young lovers) she suddenly begins to rebel, crying out, "I am half-sick of shadows!" As soon as emotion touches her personally through her interest in Lancelot, she defies the curse, and enjoys her brief hour of genuine life, though she knows it will be her last. (237)

Stevenson goes on to compare the Lady's life to that of Tennyson's own at Cambridge, and his dismissal of his earlier, less successful work, in order to face the painful realities of life. In this critical interpretation, the artist in the tower is incomplete: her work is facile and childish. Only by allowing the worst to happen - by experiencing life at both its most wonderful and painful - can she achieve greatness. The ambiguity of the line "Out flew the web and float'd wide" might therefore refer, from Stevenson's perspective, to an artist maturing, and the art finally becoming what it was always meant to be all along.

The line "Out flew the web and float'd wide" belongs to an entire stanza that sits at the heart of most critical interpretations because of its ambiguity: it is the stanza in which the Lady goes to the window to view Lancelot, and has the curse come upon her. The poem has no internality; we never get a glimpse of the Lady's thoughts aside from what she says aloud, and because of this, the stanza is shaded with deep ambiguity. It is impossible to tell whether she knows that her actions will bring the curse upon her, whether she knows that the curse will kill her, and whether this is her intention. Tennyson has deliberately shielded all of her feelings and intentions from view, and the Lady's feelings and intentions lie at the heart of critical analyses of the poem.

Stevenson's view is certainly not shared by all: Flavia M. Alaya ${ }^{35}$ expands the argument and allegory regarding the Lady of Shalott and the feelings she evokes within the reader, particularly in the context of Tennyson's other work and the critical work done by Alan Grob on Tennyson's poem "The Lotus-Eaters":

35 "Tennyson's 'The Lady of Shalott': The Triumph of Art". Victorian Poetry. Vol. 8, no. 4, winter, 1970, pp. 273-289. Web. 14 Nov. 2017. 
[l]t appears less and less possible to view the final condition of the Lady of Shalott as a female triumph but as an artistic disaster. It is certainly true that the Lady as she first appears is representative of the artist in his creative (as opposed to spectatorial) aspect, but if it is also true that she "evokes pity rather than blame" (Grob, p. 129), it may be that our pity is itself a more charitable form than blame, for our feeling such charity towards her is in great part contingent upon her own longings for a means of conjoining the outside world. Far from asking us to share with complete human sympathy in the lady's initial state, Tennyson has impressed upon us its fundamental inhumanity. (280)

Alaya goes on to argue that the pastoral detail given by Tennyson is not done in order to 'set the scene' but to evoke a repellent feeling in the setting: Shalott is so beautiful because the Lady cannot touch, reach or interact with it in any meaningful way. Furthermore, the aspects of human life that Tennyson depicts - knights, lovers, and a funeral party - all display the aspects of humanity that the embowered Lady cannot take part in: she has no knight errant with whom to enact the rituals of chivalry; she has no lover with whom to enact the rituals of romance; and when she dies, there will be nobody to mourn her and enact the funerary rituals. Not only is she embowered from nature, but also from the cultural practices that make her part of humanity. Lancelot and his image, therefore, are not just an outline of lust and love and what-mayhave-beens for the lady: he is a Messianic figure, meant to represent everything else that she has shut herself off from: faith, the heavens, and the sublime:

The sun and stars, cosmic symmetry, order and power, all unite in [Lancelot's] brilliant figure, and 
these "flashed upon the crystal mirror" the way Tennyson's own mystical experience so often "flashed" upon him, to make a morally dead phenomenon come alive with meaning and purpose. It is no accident that Lancelot's figure is a composite of reflections: the Lady had all along been contemplating reflections in a mirror, a mirror which threw back duplicates of the visual data outside her tower by detaching them from the round of life and associations with human feeling. Of the mirror's reflective power understood in these terms, however, Lancelot's is the opposite. He throws back no duplicates, only an inspiring and and all-unifying light. (284)

In other words, the curse comes upon the Lady not because of love, and not because she realizes that her own art lacks reality or vision, but because the Lady realizes exactly how cut off from all of human experience she has become in her bower. If we perceive Lancelot as sublimity, the true artist, the Lady dies of despair, realizing she can never create true art.

The general perception of these two critics, therefore, is that, in some way, the Lady represents some form of artistry; whether that is the artist's perception of reality or whether it is the artist trapped by their own limitations and lack of vision, is a choice made by the reader.

The artist in the tower is one of the major and most ambiguous elements of the critical reading of "The Lady of Shalott"; with this in mind, I'm going to perform my own critical reading in light of Pratchett's use of the text. 


\section{Light and Shadow: A Close Reading of the Lady of Shalott}

My own critical reading will be focusing a great deal less on the poem's ambiguity, and far more on the poem's use of language and imagery, particularly relating to themes of light and shadow. I will also be comparing the 1832 version of the poem to the 1842 version; while Pratchett was almost certainly taught the 1842 version, it is not inconceivable to me that he was, at the very least, aware of the 1832 version, as Pratchett demonstrated many times over his career a deep and abiding love of obscure knowledge ${ }^{36}$. Furthermore, I Shall Wear Midnight utilizes imagery from the 1832 poem far more frequently than it does the 1842 version. While the 1842 poem is considered the canonical poem, I will be using the 1832 poem as the primary text, due to Pratchett's use of the imagery from the 1832 poem.

The opening verses of the poem first introduce us to Shalott, its lands and its grounds, as well as the tower in which the Lady is imprisoned.

The poem has a theme of fecundity juxtaposed against sterility; light against shadows; movement against stillness. Part I describes in detail the Lady's lands, as beautiful and healthy, a pastoral image of pre-industrial England:

On either side the river lie

Long fields of barley and of rye,

That clothe the wold and meet the sky;

And thro' the field the road runs by

To many-tower'd Camelot;

The yellow-leaved waterlily

The green-sheathed daffodilly

Tremble in the water chilly

Round about Shalott.

Willows whiten, aspens shiver.

The sunbeam showers break and quiver

${ }^{36}$ I Shall Wear Midnight ends with Tiffany receiving a dictionary of extremely obscure words, including the outdated word "Plongeon"; a reference to her tiny curtsey to Roland throughout the novel. (348) 
In the stream that runneth ever

By the island in the river

Flowing down to Camelot. $(1-14,1832)$

Every image in this sequence evokes motion, light and fertility; the wind in the barley, the river running, the daffodils and waterlily are all described in terms of how they move and the colours they add to the picture. Even objects that are still, such as the road, are characterised by motion ("the road runs by"). Though not much actual action is taking place, there is still a strong sense of movement. The 1842 version has the same opening lines, but shifts motion from the plants to actual people:

And up and down the people go,

Gazing where the lilies blow

Round an island there below,

The island of Shalott. $(6-9,1842)$

Even so, there is still a hint of what is to come - a foreshadowing of the darkness and death that the end of this poem will bring:

Underneath the bearded barley,

The reaper, reaping late and early,

Hears her ever chanting cheerly,

Like an angel, singing clearly,

O'er the stream of Camelot.

Piling the sheaves in furrows airy,

Beneath the moon, the reaper weary,

Listening whispers, "Tis the fairy

Lady of Shalott. ' $(28-34,1832)$ 
The image of Death as a reaper is one sown in the consciousness since Roman times, ${ }^{37}$ so in a poem laden with images of fecundity and sterility, building up to a climax resulting in death, it makes logical and emotional sense to have a reaper bringing in a full harvest in the cold moonlight. Part II will invite us to associate moonlight with the Lady, but already we are having a reaper speak of the Lady in a hushed, reverent tone. If we think of the reaper as a metaphor for death, the poem is inviting us to consider the idea that her death is as inevitable as the harvest even before the curse comes upon her. In the 1842 version, while there are slight differences to the language, the general content and imagery are the same, but what is interesting is that the reaper comes after the introduction of the Lady; and rather than introducing her lying on her bed, it introduces the idea that the Lady herself is a mystery, reinforcing the idea that her death will leave her unmourned.

The movement, light and colour contrast with the end of Part II:

She lives with little joy or fear.

Over the water, running near,

The sheepbell tinkles in her ear.

Before her hangs a mirror clear, Reflecting tower'd Camelot.

And as the mazy web she whirls, She sees the surly village churls, And the red cloaks of market girls

Pass onward from Shalott.

$[\ldots]$

And sometimes thro' the mirror blue

The knights come riding two and two:

She hath no loyal knight and true,

The Lady of Shalott.

\footnotetext{
${ }^{37}$ See Chapter Four of Brent D. Shaw's Bringing in the Sheaves: Economy and Metaphor in the Roman
} World, University of Toronto Press, 2013, JStor, www.jstor.org/stable/10.3138/9781442661592 
But in her web she still delights

To weave the mirror's magic sights,

For often thro' the silent nights

A funeral, with plumes and lights

And music, came from Camelot:

Or when the moon was overhead

Came two young lovers lately wed:

"I am half-sick of shadows," said

The Lady of Shalott. $(46-54,60-72,1832)$

The instant the narrative focus of the poem shifts to the magic mirror, the delicate descriptions of movement connected to sound and colour vanish: instead there is a sense of stillness. Each half-stanza mentions only the one colour; use of verbs becomes minimal as compared to the first part; and there's a much greater focus on darkness ${ }^{38}$. The Lady's comment "I am half-sick of shadows" evokes a sterility of the mind, of action and of purpose. Also worthy of note is that while movement in the poem is now coming to a standstill, action is still taking place, but only in the mirror, at a very far distance - lovers meet, funeral processions take place, and music plays. In other words, day-to-day existence goes on, while the Lady is at a distance from it, set apart by the curse and the magic mirror.

In the 1842 version, the reference to 'joy or fear' is removed; instead, we have a statement made about the nature of the curse, which is never stated in the original, except for in the climactic stanza. In the revised poem, Tennyson writes:

There she weaves by night and day

A magic web with colours gay.

She has heard a whisper say,

A curse is on her if she stay,

\footnotetext{
${ }^{38}$ As mentioned earlier, while Part I does feature moonlight, it is only when it discusses the Lady's tower and how she is appointed; in other words, her being described under moonlight is to contrast with Lancelot's appearance in the sunlight later.
} 
To look down on Camelot.

She knows not what the curse may be,

And so she weaveth steadily,

And little other care hath she,

The Lady of Shalott. $(37-45,1842)$

This removes the ambiguity of her actions at the climax; it implies she is aware of some of the factors of the curse, though not the full details. This lack of knowledge clears up a bit of the ambiguity of the final climax.

For most of Part III, the language focuses on Lancelot - and the descriptors surrounding him are all focused on light and colour:

The gemmy bridle glitter'd free,

Like to some branch of stars we see

Hung in the golden Galaxy.

The bridle bells rang merrily

As he rode down from Camelot.

And from the blazon'd baldric slung

A mighty silver bugle hung,

And as he rode his armour rung,

Beside remote Shalott. (lines 82-90, 1832)

Lancelot is compared with flames, star clusters, meteor showers, collections of sparkling gems; when the language is not focused on light sources, it is focused on colour. More than anything, more even than the pastoral images that brought us here, Lancelot is described in bright, vivid technicolor, as if his arrival is heralding a new dawn. There is also a focus on sound as we hear descriptions of Lancelot's bugle, the sounds his armor makes, his voice, and the bridle bells. This continues the poem's sharp contrast between light and dark: Lancelot is the coming of dawn, light and music into the darkness of the Lady's existence. Differences between this and the later version are minimal; the word 'from' is substituted with 'to', changing his direction. There does, 
in fact, seem to be a greater implication in the later version that Shalott is on the very outskirts of Camelot.

Furthermore, there is also a focus on reflections: all of the metal Lancelot carries reflects the sunlight, and he himself is reflecting into the crystal mirror:

His broad clear brow in sunlight glow'd;

On burnish'd hooves his war-horse trode;

From underneath his helmet flow'd

His coal-black curls as on he rode,

As he rode down from Camelot.

From the bank and from the river

He flash'd into the crystal mirror,

'Tirra lirra, tirra lirra:'

Sang Sir Lancelot. $(100-108,1832)$

Again, the 1842 version changes very little; he is now riding 'to' Camelot, and the second-last line changes to "Tirra lirra' by the river".

All these intricate descriptions of Lancelot, his horse, his gear and the light surrounding him, serves as a sharp contrast to when the Lady makes her decision to break away from the loom and magic mirror. In possibly the most famous stanza of the poem, all of the descriptive language is reduced to the very barest of bones as we see the effects of her actions:

She left the web, she left the loom

She made three paces thro' the room

She saw the water-lily bloom,

She saw the helmet and the plume,

She look'd down to Camelot.

Out flew the web and floated wide;

The mirror cracked from side to side;

'The curse is come upon me,' cried 
The Lady of Shalott. $(109-117,1832)$

The stanza in which all the important action takes place is surprisingly suggestive. Up to this point, in terms of action, very little has happened: day has broken, night has fallen, and Lancelot is now riding; most of the text has gone to adjectives, detailing how things looked or sounded. So when the bulk of the action - in fact, the most important action of the poem - takes place, there are no adjectives whatsoever. It is entirely up to the reader's imagination what it looks like. This is again, a place where Tennyson has changed little between versions - the 1842 version simply adjusts "water-lily" to "waterflower."

This is the stanza that, as mentioned earlier, is at the heart of all critical analyses due to its ambiguity, and it is clearly an intentional ambiguity. If we view the text, as many do, as being a treatise on the artist, the ambiguity of her actions may be intended as a kind of proto-Death of the Artist: an argument that we can never really know the intentions of any art produced or any action taken, so any interpretation must come from outside. However, the 1842 version does introduce the fact that the Lady is at the very least aware of the curse and what will bring it upon herself, if not aware of what it will cause, removing some of that tantalising ambiguity. While the 1832 version is ambiguous in the extreme, in the 1842 version Tennyson seems to have deliberately invoked motive for the Lady. She does not know the effect of her actions, just as an author does not know how their art will be appreciated or interpreted after they have created it.

In Part IV, the part of the poem in which the Lady moves to a boat, we return to the language-use of the previous sections, but in a slightly more muddied fashion. While the reader does not receive a clear idea of where, how or why the Lady goes or what she does, Tennyson does make use of his first extended simile:

As when to sailors while they roam, By creeks and outfalls far from home, Rising and dropping with the foam, From dying swans wild warblings come, 


\section{Blown shoreward; so to Camelot}

Still as the boathead wound along

The willowy hills and fields among,

They heard her chanting her deathsong,

The Lady of Shalott. $(145-153,1832)$

This extended simile is missing entirely from the 1842 version, which results in a final section that is much clearer in terms of action, place and setting; the simile itself immediately draws our attention to the notion of dying swans and water, invoking the manner of the Lady's death. The 1842 version, without the extended simile, instead lets the imagery speak for it. It is possible Tennyson felt that the extended simile not only confused the action but also, as it were, played his hand rather too soon.

In this final part, rather than focusing on light, shadow, fecundity and sterility, there are two different ideas I would like to explore. Firstly, the comparison between the Lady and the idea of a swan. The classical myth of the swansong is one that is culturally embedded in our imagination - that every mute swan sings one last time, beautifully, before they die. ${ }^{39}$ The Lady's choice of clothing invokes the image of a swan's wings:

A cloudwhite crown of pearl she dight,

All raimented in snowy white

That loosely flew (her zone in sight

Clasp'd with one blinding diamond bright)

Her wide eyes fix'd on Camelot,

Though the squally east-wind keenly

Blew, with folded arms serenely

By the water stood the queenly

Lady of Shalott. (lines 127-135, 1832)

It is interesting that after describing Lancelot in terms of meteors and clusters of stars, to describe the Lady's girdle, Tennyson uses the word 'zone', which can also refer to

\footnotetext{
${ }^{39}$ A myth clearly perpetuated by people who have never encountered real swans.
} 
the chain of stars that mark Orion's belt. In other words, a valid interpretation might be that the Lady longs for Lancelot, not because she lusts for him, but because she wants to be like him. Furthermore, all of her clothes are snow white raiment (a priestly cloth), and the fact that they're being billowed about by the storm is, combined with the extended simile, likely meant to invoke the image of the singing swan about to die. The 1842 version lacks the word 'zone', but still keeps the use of white clothing being blown "from left to right" and invokes the concept of her "singing in her song she died", keeping the imagery of a swansong.

The second aspect of Part IV I want to discuss is the encroachment of urbanisation. As the Lady passes into Camelot, she sees the lush, pastoral fields of Shalott give way to urban Camelot, and it is difficult not to read this as a Romantic writing not just the death of the Lady but also the death of England as it once was:

A longdrawn carol, mournful, holy, She chanted loudly, chanted lowly, Till her eyes were darken'd wholly, And her smooth face sharpen'd slowly, Turn'd to tower'd Camelot: For ere she reach'd upon the tide The first house by the water-side, Singing in her song she died, The Lady of Shalott.

Under tower and balcony, By garden wall and gallery, A pale, pale corpse she floated by, Deadcold, between the houses high, Dead into tower'd Camelot. Knight and burgher, lord and dame, To the planked wharfage came: Below the stern they read her name, 
It is literally not until the Lady reaches the first house, the first sign of urbanised England, that she dies, so here we can read a further expansion on the theme of fecundity and sterility: that the ultimate opponent of fecundity is urbanisation. While an argument can be made that she is travelling to Camelot, England's romantic heart, I argue against this, for two reasons: the first is that Camelot is barely described throughout the text; while the pastoral fields are beautifully lush, Camelot is hardly touched on. Secondly, the people of Camelot are described as "wellfed wits"; when the Lady writes a simple message for them to understand, they are made out as not having been able to understand it at all. While Camelot may be the home of the Romantic heart of England, Tennyson describes its people as unable to understand the artistry of the Lady, and it is the people that Tennyson is critiquing here.

There is also an implication of a journey to the Underworld - the Lady's journey on the vessel is similar to the journey taken on Charon's boat across the river Styx in many Classical plays and poetry. Traditionally, those about to embark on the river Styx must also drink of the river Lethe, losing their memories of their past life, and as the Lady journeys in her boat, she not only loses her life, but also her identity, becoming merely an object.

The 1832 poem ends with all the "wellfed wits" of Camelot blessing their stars and puzzled to learn only the bare bones of the Lady's story; that the charm has broken and taken her life in water. There is nothing to fear, yes - but also nothing to mourn. That is the sorrow of the Lady's fate - they may pity her, but they cannot mourn her. Nobody can, because we don't even know her name, or her motivations.

The 1842 version has a slightly different ending, with a slightly different focus:

Out onto the wharfs they came, Knight and burgher, lord and dame, And round the prow they read her name,

The Lady of Shalott. 
Who is this? And what is here?

And in the lighted palace near,

Died the sound of royal cheer;

And they cross'd themselves for fear,

All the knights of Camelot.

But Lancelot mused a little space;

He said, "She has a lovely face;

God in his mercy lend her grace,

The Lady of Shalott." (159-171, 1842)

Here the dismissive tone of the peoples of Camelot is replaced by peopling the wharf with the horrified knights of Camelot; the death of the Lady is the death of their happiness. Possibly, also, her death represents the death of purity and the death of the Golden Age of Camelot, hence the visual association of her with the swan. Swans are associated with both eternal love, due to the myth that they mate for life, and with kingship, due to the longstanding English law that the monarch may claim any unclaimed swan as their own. Lancelot giving the Lady her final honors ties back into the inspiration for her story - that of the Fair Maid of Astolat. It should also be noted that while the theme of urbanisation is mostly removed in the 1842 version, the implication of entering the underworld or death via a river remains; she still dies singing her song in a river which may be the one running through Camelot but may also be allegorical of the river Styx.

Which leads to the question: what does Pratchett do with the same material?

\section{The Melting Girl: Subversion in the Disc}

Letitia Keepsake is introduced in the fourth Tiffany Aching book I Shall Wear Midnight. She is Roland's fiancée, and right from her first appearance, every time Tiffany sees her or thinks about Letitia, she is associated with watery words - "wet", "dripping", "squelchy". Letitia is explicitly compared to a water nymph (230), and it is pointed out she wears almost entirely pallid, pastel colours. Her mother keeps her 
locked in the Maid Tower, unable to leave due to her guards, and drugs her food and milk (233-234). Finally, Letitia mentions that she is confined, artistically, to watercolors and not even permitted to attempt charcoal sketches (235). Letitia is Pratchett's lady in the tower.

Before we discuss Letitia in any greater depth, it is helpful to discuss Pratchett's other evocation of the artist in the tower in the form of Leonard of Quirm, who was intended mostly as a reference to Leonardo da Vinci, but with elements of Michelangelo, Tesla and a bit of Charles Darwin (he has the latter two's fondness for pigeons). He is held captive by the Patrician of Ankh-Morpork, Havelock Vetinari, but in The Fifth Elephant, the narration has this to say of his imprisonment:

Leonard of Quirm never dreamed that he was a prisoner. If anything, he was grateful to Vetinari for giving him this airy work space, and regular meals, and laundry, and protecting him from those people who for some reason always wanted to take his perfectly innocent inventions, designed for the betterment of mankind, and use them for despicable purposes. It was amazing how many of them there were - both the people and the inventions. It was as if all the genius of a civilization had funnelled into one head which was, therefore, in a constant state of highly inventive spin. Vetinari often speculated upon the fate of mankind should Leonard keep his mind on one thing for more than an hour or so. (80)

If we compare Leonard's imprisonment with both the Lady's and with Letitia's, we see a contrast start to emerge: Leonard is not treated or regarded as a prisoner. In fact, Leonard is presented as the introverted genius; Letitia, on the other hand, is presented as horribly lonely and unhappy. Leonard also is presented as multidisciplinarian in his talents: he is an artist, an alchemist, a mathematician, a scientist and an engineer. It is 
through his various skills and talents that he is able to metaphorically escape his imprisonment. Letitia and the Lady, on the other hand, are artistically stifled, being given only one recourse to express how they feel. Pratchett is here making a commentary on how we regard the artist in the tower: the masculine artist in the tower is the reclusive genius, a male hero; he is da Vinci, Tesla, Darwin, Sherlock Holmes, Merlin, and more. The feminine artist in the tower is a threat to patriarchal empowerment, so not only is she locked away, her methods of expressing herself must also be locked down, too. The most iconic image of the Lady's imprisonment and artistic expression is also her primary mode of escapism: the magic mirror, and Pratchett's method of evoking the Lady's magic mirror appears early on in I Shall Wear Midnight.

Tiffany Aching is heading to Ankh-Morpork to tell Roland of his father's death, when she accidentally lands on a mail coach who has "jumping bones." Due to the coachman's condition, he drops a disco ball on the ground:

[T]he coachman rummaged among the straw inside, bringing out the mirror ball, holding it aloft like a rare jewel which, indeed, it resembled. It filled the world with sparkling light, dazzling the eyes and sending beams of flashing rays across the landscape. And at this point the man screamed in pain and dropped the ball, which shattered into a million pieces, filling the sky just for a moment with a million images of Tiffany, while he, curling up, landed on the road[.] (106-107)

The million images of Tiffany reflected and refracted in a mirror seem to foreshadow her role as the Lancelot to Letitia's Lady, by hearkening to Tennyson's description of Lancelot's appearance being reflections upon reflections:

From the bank and from the river

He flash'd into the crystal mirror,

"Tirra lirra," by the river, 
The breaking of the mirror ball also seems to evoke the moment the curse comes upon the Lady - "The mirror crack'd from side to side". This can be seen from two perspectives: on the one hand, Tiffany is under the influence of a curse at this moment in the narrative, and it is while the mirror ball is cracked that she first meets the Cunning Man, the novel's antagonist and the embodiment of hatred for witches and bigotry in general. On meeting him, Tiffany has some idea of what is in store for her - a kind of reference to the superstition of 'seven years bad luck' for breaking a mirror. On the other hand, it can also be seen as a statement of purpose for what is to come: Pratchett is already setting up expectations of subverting stories that are not yet in motion, and that are only apparent on rereading. The broken mirror ball is solved in an unexpected fashion, for example. After Tiffany has fixed the man's "jumping bones," she finds that her allies, the Nac Mac Feegle, have mended the mirror ball:

A little tinkling sound made Tiffany look behind them, where the mirror ball, apparently unharmed, was spinning gently and, if you looked carefully, just above the dirt.

$[\ldots]$

"Did you stick it back together again?"

"Oh aye," said Rob Anybody happily from behind the ball. (113)

In a book filled with omens, to the point that one of Tiffany's recurring statements is "you picked the omens that worked" (315), this omen sticks out. The subversion is not that the mirror breaks - there is nothing at all surprising about a mirror breaking after all but that Tiffany's destructive friends the Nac Mac Feegle repair it, foreshadowing, perhaps, Tiffany's own repair of her relationship with Letitia, and Letitia's status as an intertextual reference to the Lady of Shalott. 
When Tiffany gets a chance to have an extended look at Letitia - and starts to feel genuine compassion for her - one of the observations she makes is "You could add, too, that there was so little of her that in a storm it might be quite possible that she would snap" (195). Given how the final part of "The Lady of Shalott" takes place during a sudden high storm, this reads as more than a slight nod to the poem. It's also worth mentioning that Roland and Letitia are in Ankh-Morpork to buy a tiara for Letitia:

The tissue paper was carefully pulled off, and in the light of the lamps something sparkled so brilliantly that it seemed not only to reflect the light but to generate it too, somewhere inside its glowing stones. It was a tiara. (135-136)

In the original 1832 version of "The Lady of Shalott", the Lady is noted multiple times as wearing a tiara of some variety. At the end of Part I:

A pear garland winds her head:

She leaneth on a velvet bed,

Full royally apparelled,

The Lady of Shalott. $(33-36,1832)$

And again at the start of Part IV:

A cloudwhite crown of pearl she dight,

All raimented in snowy white

That loosely flew (her zone in sight

Clasp'd with one blinding diamond bright)

Her wide eyes fix'd on Camelot. (127-131, 1832) 
In other words, the choice to give Letitia a beautiful tiara as a wedding gift continues Pratchett's trend of evoking events and descriptions from the poem itself.

After her visit to Ankh-Morpork, Tiffany has it made clear to her that a being known as the Cunning Man has risen again to take revenge against every witch alive, and is focusing primarily on Tiffany herself, as he sees in her the embodiment of the witch who created him once, long ago (164). "Poison goes where poison's welcome" is a recurring motif in the novel, in reference to the poison of bigotry and ignorance, and Tiffany becomes subject to both. Due to this, she is locked up in the dungeons of the castle, and it is here she has her first real conversation with Letitia:

It was Letitia, the bride-to-be, all in white and all in tears. She reached the bars of Tiffany's cell, hung onto them, and carried on crying: not big sobs, but just an endless snivelling, nose-dripping, fumbling-inthe-sleeve-for-the-lace-hanky-that-is-already-totallysoaking-wet kind of tears.

The girl didn't really look at Tiffany, just sobbed in her general direction. "I'm so sorry! I really am very sorry! What can you think of me?" (222)

The connection of Letitia in white with endless tears raining down is a strong connection to the storm the Lady goes through in Part IV of the poem. Given that Letitia is also noted to perpetually wear white and have soaked herself from crying, the imagery here invokes the Lady's appearance just as she boards the boat.

Before Letitia has a chance to explain what she is apologizing for, the Duchess and Roland arrive in order to, respectively, threaten Tiffany and protect Letitia. It is here a passage takes place that highlights both the manner in which Letitia subverts many of the aspects of the traditional Lady in the Tower, as well as one of the more notable aspects of Pratchett's writing: 
"This is not going to be about spinning wheels, is it?"

Tiffany asked. [...]

"I shall tell the men to search the castle and destroy every single one of them!" said the Duchess. [...]

Letitia, who had been standing in a state of snuffle, managed to say, "Mother, you know you've never let me touch a spinning wheel."

"And you never will touch a spinning wheel, ever, Letitia, never in your life. Such things are there for the labouring classes. You are a lady. Spinning is for servants." (225-226)

While, granted, the Lady is creating a tapestry, not spinning thread, the implication that textiles are beneath Letitia is an interesting subversion of the story, especially considering that on the same page, we learn that Roland's mother spun; Pratchett is using the story to make a commentary on class structure and the people who enforce it. This is a common aspect in Pratchett's writing across all of his Discworld novels.

Following this conversation, Tiffany realises that Letitia has something magical to her, resolves to find out where and why, and makes her escape from the dungeon. It is here we have a reference to another Victorian author:

And that is why Tiffany looked up and saw, high above her, that little patch of blue which a prisoner calls the sky, but which she, as soon as it was dark enough, intended to call the exit. (232)

This refers to Oscar Wilde's "The Ballad of Reading Gaol" (1898), in which "that little tent of blue we prisoners call the sky" (15-16) is a recurrent theme, and it's intriguing that Pratchett picks Wilde to reference. Like Tennyson, Wilde was fascinated by his own era, and much of his major writing was taken up in discussing it; his plays are all gentle satires on the class and social strata of Victorian England. So to use Oscar Wilde's 
poem on the damage of wrongful imprisonment and the harmfulness of the death penalty is a fascinating choice when Tiffany is just about to confront Letitia for the harm Letitia has wrought upon Tiffany's life and upon the peoples of the Chalk.

After this moment, Tiffany and Letitia have a talk in which it is discovered that Letitia tried to make people ignore Tiffany (and, it is later discovered, accidentally summoned the Cunning Man). Tiffany and Letitia also start to bond over shared experiences $(235,239,241)$. While the Lady is never given a specific hair colour, ${ }^{40}$ Letitia's blonde hair colour ties into a recurring theme within the novels: fairy tale hair colouring and how it paints our perceptions as children. In The Wee Free Men, Tiffany notes that blondes and redheads are the people who are the princesses and the heroes, whereas she has brown hair and eyes; so, since she couldn't be a princess or a prince, she would be the witch (38). This leads to a conversation between Tiffany and Letitia, where they discover that they grew up with the exact same storybook, eventually prompting Tiffany to try and convince Letitia that she has magical potential:

"You are a witch." The words came out of Tiffany's mouth all by themselves, unable to stay in the privacy of her mind.

The girl looked at her in astonishment. "Don't be silly," she said. "We both know how it goes, don't we? Long blonde hair, milk-white skin, noble - well, a reasonably noble birth - and rich, at least technically. I'm officially a lady."

"You know," said Tiffany, "maybe it's wrong to base one's future on a book of fairy stories." (244)

Letitia's acknowledgement of her place in a traditional narrative - as well as Tiffany's rejection of it - form the basis of their friendship, and also form part of the ongoing subversion of Letitia's story as the Lady of Shalott. Letitia is not willing to merely allow a

\footnotetext{
40 Though the painters who were especially taken with the Lady of Shalott seemed to usually cast her as a blonde or a redhead; the most famous painting of the Lady of Shalott in her boat, by John William Waterhouse (1888), portrays her as a redhead.
} 
curse to dictate her life, or social strata to dictate her friends; she shows a desire to fight back against what is expected or perceived of her, just as Tiffany does.

As Letitia is the Lady, Tiffany is her Lancelot; she is the one who invites her out to the world by helping her escape from her tower, and the one who starts a friendship with her. Letitia also represents the poem's themes of darkness and sterility, while Tiffany is associated with light and fecundity. When Tiffany and Letitia journey to Letitia's girlhood home of Keepsake Manor, this is how the text describes it:

\begin{abstract}
At last the cranky doorknob turned, opening into a long corridor that smelled of...that smelled of...that smelled of old. That was the only way to describe it, but if you had enough time to think, you would say it was a mix of dry fungi, damp wood, dust, mice, dead time and old books, which have an intriguing smell of their own. That was it, Tiffany decided. Days and hours had died quietly in here while nobody noticed.
\end{abstract} (243)

The place with the most association with Letitia - the place Tiffany describes as "her [Letitia's] place" (244) - is the one described as an old, dark place, with dead grass, haunted by ghosts whom Letitia has helped. The Lady may be half-sick of shadows, but for Letitia, this is her home, and where she is most happy. As for sterility, Letitia's sad plea to Tiffany regarding art gives plenty of evidence in that regard:

"The most I'm allowed to do is paint pictures and only watercolors at that. Not even charcoal sketches!" (235)

She, like the Lady, is artistically sterile. Contrast these associations of darkness and sterility with Tiffany, who spends much of the book musing on fire, her favourite 
element, and its uses. ${ }^{41}$ Unlike in the previous two books, Tiffany's animal of association is not the White Horse of the Chalk Hill, but the golden hare, the animal that runs into the fire heedless of the danger.

Tiffany is also associated with fecundity. After a teenage girl named Amber is beaten and miscarries her baby, Tiffany is required to bury the aborted child:

In the hazel woods there was a clearing of flowers from early spring to late autumn. There was meadowsweet and foxglove and old man's trousers and Jack-jump-into-bed and ladies' bonnets and three-times-Charlie and sage and southernwood and pink yarrow and ladies' bedstraw and cowslips and primroses and two types of orchids.

$[\ldots]$

The seeds had been expensive to buy and she had had to go all the way to Twoshirts to get them, but she had vowed that every summer the brilliance in the wood would remind people. $(60-61)$

In other words, Tiffany has been responsible for growing a large surface area of beautiful perennials ${ }^{42}$ and shrubs in order to make a point to her community at large. It is worth noting that as well as being perennials, most of the flowers and their names here evoke either sex (orchids, Jack-jump-into-bed) or clothing (foxgloves, ladies' bonnets), adding another element to the implication of Tiffany's connection to the land and fecundity. It is likely no accident that the older Tiffany who appears throughout the book is noted as bearing herself proudly, like Granny Weatherwax (who is an old maid),

\footnotetext{
${ }^{41}$ Tiffany's association with fire throughout the book makes Letitia's plea to do a charcoal sketch an even more interesting statement - allegorically, she is stating a desire to be Tiffany, in much the same way that Tennyson's use of the word 'zone' implies a similarity or desire for similarity toward Lancelot with the Lady.

${ }^{42}$ Breed of orchids and foxglove are not specified, and Old-Man's-Trousers, Jack-jump-into-bed and three-times-Charlie appear to be Discworld-only species, so we can't know for certain if those were all perennials, but given the implication that Tiffany chose long-lasting species so she could save up money to buy them again when they died off, it seems likely.
} 
but also giving an impression similar to Nanny Ogg (who is a mother many times over) (332). Furthermore Tiffany, as a midwife, is associated far more strongly with birth and death ${ }^{43}$ and with the comings and goings of life than Letitia, who is, appropriately, associated more with the afterlife and the care of it, building on the poem's allegorical associations with the Rivers Styx and Lethe.

It should be stressed though that Letitia does not die. In fact, Letitia could be described as transformed by the events of the book: while the Lady passes through water and dies, Letitia passes through fire, and lives. Tiffany, her Lancelot, takes her hand during the final climax - where Letitia, Tiffany and Roland, Letitia's fiancé run from the Cunning Man into the blazing heat of the burning stubbs - and as they leap over the fire, Tiffany marries Letitia and Roland:

\begin{abstract}
"Back to the hells you came from, you Cunning Man," she yelled above the flames. "Leap, knave! Jump, whore?" she screamed again. "Be married now forevermore!" And this is a wedding, she said to herself. A fresh start. And for a few seconds in the world, this is a place of power. (319)
\end{abstract}

After being wed and defeating the Cunning Man, Letitia confronts Tiffany over the words used - specifically Tifffany's use of the word 'whore.' Letitia notes that she thinks it is a "bad" word (323) and Tiffany acknowledges it, but also comments that the use of words changes over time, and asks if Letitia would be able to be "buxom", explaining the old meaning was to be kind, understanding, and obedient. Letitia's acknowledgement that she can be the first two "at least", seems to be a play on the common interpretation of "The Lady of Shalott" as a parable regarding sexual desire in women, as well as how "lady-in-towers" are frequently there due to their disobedience. Here, Pratchett celebrates Letitia's willingness to be disobedient and has her refer to Nanny Ogg, who

\footnotetext{
${ }^{43}$ Pratchett's midwives are almost all midwives of the early 20th century, involved both in the birthing of babies and the laying out of the dead.
} 
is frequently noted as being, in Discworld terms, no better than she ought to be, in respectful and approving terms.

The fact also that Tiffany dispels the Cunning Man with a wedding is notable for two reasons. Firstly, within the text itself, when Tiffany asks Miss Smith what would happen if the Cunning Man caught her, Miss Smith answers "Well I suppose from his point of view, it will be rather like a wedding. From your point of view, it will be exactly like being dead" (165), meaning that in using a wedding to dispel him, she has turned the tables on the Cunning Man. But it is also relevant in terms of the "The Lady of Shalott," due to how the Lady dies. Tennyson goes into great detail with her swan-like apparel, which appears, to a modern reader, as almost marital ${ }^{44}$; Letitia is noted as wearing a 'billowing' night gown. Both Letitia and the Lady are dressed for a marriage, but only one of them gets a wedding.

When Letitia is formally wed, she is noted to have slightly frizzled hair (hidden by her tiara); the fire has left its mark on her, and when Tiffany goes to speak to Letitia and Roland, this is revealed:

\begin{abstract}
"About last night..." [Roland] began nervously. "Er, it did happen, didn't it? I mean, I remember the pigsty, and we were all running, but..." His voice faded away. Tiffany looked at Letitia, who mouthed the words, "I remember everything!" (327)
\end{abstract}

This reveals, as Tiffany notes later, that Letitia is, from her crown to her boots, most certainly a witch; Roland, dragged through while hungover and against his will, remembers nothing of their confrontation with the Cunning Man. Letitia, transformed by the fire, remembers everything.

In the final Tiffany Aching book, The Shepherd's Crown, and the only Pratchett book published posthumously, Tiffany and the other witches have to deal with an

\footnotetext{
${ }^{44}$ And may also have at the time - Queen Victoria's white dress is often cited as being the dress that started the slow shift toward white as the traditional marital wedding gown. See:

http://thedreamstress.com/2011/04/queen-victorias-wedding-dress-the-one-that-started-it-all/ (retrieved 14 Dec 2017).
} 
incursion of Elves. Queen Magrat invites Letitia to help (268). Letitia is at first reluctant, and it is interesting to note here that in many ways, Letitia and Magrat are of a 'type' in terms of Discworld heroines; Pratchett stated many times in his life that he was incapable of writing what he called 'soft' women, stating that they were all 'tough as old boots' underneath. This is certainly true of both Letitia and Magrat, the latter of whom was once noted as being the 'wet hen' of the Lancre coven and who, nevertheless, shot an Elf in the eye with a crossbow bolt ${ }^{45}$. When Letitia fights, this is how Pratchett describes her:

[Letitia] was tumbling from her horse, determination in her face, borrowed chainmail over her dress. She somehow flowed through the elves - there was a certain magic to it as if she were some goddess of water, streaming everywhere: no thought to it, but no stopping it either.(307)

With this final passage, the full subversion of the story is revealed: not only is Letitia not dead, despite her clear similarities to the Lady, she is empowered by water, she commands it. Having been through fire and magic and come out the other side, Letitia is no longer the damp, slightly colourless water nymph of I Shall Wear Midnight; she is a Baroness and a water goddess in one. Unlike the Lady of Shalott is, Letitia's imprisonment is not from a curse, but from her upcoming nuptials; she is not a mysterious, nameless, cursed fey, whose death is left ambiguous, but a woman with dreams, aspirations and family, who escapes her tower not through the enlightenment or folly of death, but through the empowerment of female friendship. She is a rejection of the Arthurian archetype whilst embracing how subverting these archetypes can change stories for the better.

${ }^{45}$ Lords and Ladies, 234 


\section{$\underline{\text { Conclusion }}$}

In his speech "Imaginary Worlds, Real Stories", Pratchett says:

"I did not study folklore any more than a butterfly studies flowers. I certainly wasn't in any sense scholarly. But as a young writer - and a journalist, because journalists certainly think in terms of 'story shapes' [...] I started noticing patterns and similarities." (166)

It is this tendency that is at the heart of Pratchett's work; his tendency to think in the shape of a story, regardless of what story it is. His works tend toward the intertextual, the allusive, the metonymical and the metaphorical, and this has drawn and is drawing many new critical responses and interpretations.

A cynic might argue that the recent interest in Pratchett is due to his death and the circumstances surrounding it, including his demand for the British government to legalize assisted suicide, and his invitation to speak at the Dimbleby lectures, a privilege previously saved only for the best and brightest of the medical profession. It would be disingenuous to deny that this fascination with Pratchett's politics may make up a portion of the readings into his work; as mortals, we have a fascination with death and the circumstances surrounding it, which may explain why Pratchett's Death is one of his more popular characters. However, it would be equally dismissive to Pratchett's own artistic merit as an author and as a crafter of stories to claim that as the only reason for the growing critical interest in his work. At the end of the day, Pratchett is far more than his death.

Pratchett's ability to form stories that are intertextual and allusive in style as well as being metonymical and metaphorical in image is a large part of his popularity. Even if a reader does not understand the reference, they understand the meaning behind the reference. A reader may not know the full story behind the Fisher King, but they understand that Tiffany's relationship to the Chalk, and the Wintersmith's relationship to 
the mountains are tied together in a near-mystical way. A reader may not remember that Lancelot, Guinevere and Arthur formed one of the basis of one of the most important chivalric romances of the Medieval period, but they recognize the story being told between Jeannie, Rob Anybody, and Tiffany. And a reader may not have read "The Lady of Shalott," but they know the type of character Letitia embodies, and recognize, symbolically, the importance of her passing through fire to become a goddess of water. This ability to utilize these narratological tools is what has given rise to the critical analysis of his characters as cultural palimpsests, and what gives rise to my argument for Tiffany Aching and her stories as Arthurian palimpsests.

If imitation symbolizes the artistic ability to reform and reshape stories to say something new and unique, even while the story shape itself remains the same or similar to what it was before, then Pratchett is a master imitator, and it is a craft we should start recognizing. Too much time is spent attempting to find the originals and belying the imitators: perhaps we should chronicle the differences between each imitation, and start recognizing the craft of imitation for what it is, the craft of white knowledge. 


\section{Works Cited}

Abbott, William T. "White Knowledge and the Cauldron of Story: The Use of Allusion in Terry Pratchett's Discworld". Master of Arts thesis, East Tennessee State University, 2002,

\section{https://dc.etsu.edu/cgi/viewcontent.cgi?article=1787\&context=etd. Accessed 9}

Feb 2018.

Alaya, Flavia M. "Tennyson's 'The Lady of Shalott': The Triumph of Art”. Victorian Poetry. Vol. 8, no. 4, winter, 1970, pp. 273-289. 14 Nov 2017.

Andersson, Lorraine. "Which Witch is Which? A Feminist Analysis of Terry Pratchett's Discworld Witches." MA thesis. University of Halmstad, 2006. 9 Mar 2017.

Aronstein, Susan. Hollywood Knights: Arthurian Cinema and the Politics of Nostalgia. First edition, Palgrave Macmillan, October 2005. . Armstrong, Dorsey. "The (Non-)Christian Knight in Malory: A Contradiction in Terms?" Arthuriana, vol. 16, no. 2, Summer 2006, pp. 30-34. 21 Mar 2017. The Blues Brothers. Directed by John Landis, produced by Robert K. Weiss, Universal Pictures, June 201980.

Boulding, Lucas. “I can't be having with that': The Ethical Implications of Professional Witchcraft in Pratchett's Fiction." Gender Forum. 2015. 9 Mar 2017. Breebart, Leo and Mike Kew. "Words from the Master" The Annotated Pratchett File v9.0, I-space.org, https://www.Ispace.org/books/apf/words-from-themaster.html. 9 Feb 2018. 
Browning, Robert. "Childe Roland to the Dark Tower Came". Bartleby.com, http://www.bartleby.com/246/654.html. 01 Apr 2017.

Bulgozdi, Imola. "Some Genetics Are Passed On Via The Soul': The Curious Case of Susan Sto Helit”. Gender Forum. 2015. 9 Feb 2018.

Butler, Andrew M., Edward James and Farah Mendlesohn, eds. Terry Pratchett: Guilty of Literature. Reader: Science Fiction Foundation, 2004.

"Childe Rowland". Sacred-texts.org http://www.sacredtexts.com/neu/eng/eft/eft22.htm Accessed 7 Sept 2017.

Dirty Harry. Directed and produced by Don Siegel, Warner Bros, 1971.

Donaldson, Eileen. “'Nae King! Nae Quin! Nae Laird! Nae Master!' Childhood Agency in Terry Pratchett's The Wee Free Men." Mousaion. vol. 33, no. 2, April 1, 2015, pp. 56-72. 9 Mar 2017.

Eliot, T. S. "The Waste Land". Poetryfoundation.org https://www.poetryfoundation.org/poems/47311/the-waste-land-56d227a99ddeb. Accessed 31 Aug 2017.

Excalibur. Directed by John Boorman, Orion Pictures, 1981.

Field, Rosalind. "The Curious History of the Matter of England". Boundaries in Medieval Romance, edited by Neil Cartlidge, Boydell \& Brewer, D. S. Brewer, 2008, pp. 29-42. 10 Jan 2018.

Frazer, James G. The Golden Bough, Vol. 1. 3rd Edition. MacMillan Company. 1936.

Fries, Maureen. "The Lady to the Tramp: The Decline of Morgan le Fay in Medieval Romance." Arthuriana. Vol. 4, no. 1, 1994, pp. 1-18. 14 Mar 2017. 
George Bernard Shaw. St. Joan. 1946, Penguin Books, 1923.

Goodrich, Peter H. "The Erotic Merlin". Arthuriana, vol. 10, no. 1, 2000, pp. 94115. 15 Sept 2017.

Gowans, Linda. "Malory's Sources - And Arthur's Sisters - Revisited." Arthurian Literature XXIX, edited by Elizabeth Archibald and David S. Johnson, vol. 29, Boydell and Brewer, 2012, pp. 121-142. 8 Sep 2017.

Haberkorn, Gideon. "Debugging the Mind: The Rhetoric of Humor and the Poetics of Fantasy". Critical Explorations in Science Fiction and Fantasy. Vol. 45, 2014, pp. 160-188.

- - - . "Cultural Palimpsests: Terry Pratchett's New Fantasy Heroes”. Journal of the Fantastic in the Arts. Vol. 18, no. 3, 2007, pp. 319-339. 10 Jan 2018. Jackson, Rosemary. Fantasy: The Literature of Subversion. London: Methuen, 1981.

Kaufman, Amy S. "The Law of the Lake: Malory's Sovereign Lady”. Arthuriana. Vol. 17, No. 3, Fall 2007, pp. 56-73. 21 Mar 2017.

Kelly, Kathleen Coyne. "Malory's Body Chivalric". Arthuriana. Vol. 6, No. 4, Winter 1996, pp. 52-71. 21 Mar 2017.

Kennedy, Beverley. "Adultery in Malory's Le Morte D'Arthur". Arthuriana. Vol. 7, No. 4, Winter 1997, pp. 63-91. 21 Mar 2017.

Knox, John. "The First Blast of the Trumpet Against This Monstruous Regiment of Women", 1558. http://www.swrb.com/newslett/actualNLs/firblast.htm. 18 Mar 2018. 
Kristeva, Julia. Desire in Language: A Semiotic Approach to Literature and Art.

Translated by Thomas Gora, Alice Jardine, Leon S. Roudiez. Columbia University Press, 1980.

Lacy, Norris J., and Geoffrey Ashe. The Arthurian Handbook. Garland Publishing Inc., 1988.

C. S. Lewis. The Allegory of Love: A Study in Medieval Tradition. Oxford University Press, 1936.

Labyrinth. Directed by Jim Henson, produced by Henson Associates Inc, Lucasfilm Ltd, 1986.

Lewis, Helen. "The Politics of Pratchett." New Statesman. 19 Nov. 2012: n.pag. 14 Mar 2017. <http://www.newstatesman.com/culture/2012/11/politics-pratchett> Lourie, Margaret A. "Below the Thunders of the Upper Deep: Tennyson as a Romantic Revisionist." Studies in Romanticism. Vol. 18, no. 1, Spring 1979, pp. 3-27. 15 Nov 2017.

The Lion King. Directed by Roger Allers, Rob Minkoff, produced by Walt Disney Studios, Buena Vista Pictures, 1994.

Malory, Sir Thomas. Works. Ed. Eugène Vinaver. USA: Oxford University Press, 1971.

Martinez Alfaro, María Jesús. "Intertextuality: Origins and Development of the Concept". Atlantis. Vol. 18, no. 1/2, June-December 1996, pp. 268-285. 10 Apr 2017.

McGillis, Roderick. "The Wee Free Men: Politics and the Art of Noise". Critical Explorations in Science Fiction and Fantasy. Vol. 45, 2014, pp. 15-25. 
Neil Gaiman. “Neil Gaiman: 'Terry Pratchett isn’t jolly. He’s angry’”. The Guardian. Wednesday 24 September, 2014.

https://www.theguardian.com/books/2014/sep/24/terry-pratchett-angry-not-jollyneil-gaiman

Nitze, William. A. "The Fisher King in the Grail Romances." Modern Language Association. Vol. 24, no. 3, 1909, pp. 365-418. 5 Jun 2017.

George Bernard Shaw. Saint Joan. Project Gutenberg of Australia, Oct. 2002.

Retrieved 12 Jul 2017.

Oakes, Leimomi. "Queen Victoria's Wedding Dress: The One That Started It All".

The Dreamstress. Apr 18, 2011, http://thedreamstress.com/2011/04/queen-

victorias-wedding-dress-the-one-that-started-it-all/

Ortner, Sherry B. "Is Female to Male as Nature Is to Culture?" Feminist Studies.

Vol. 1, No. 2, Autumn 1972, pp. 5-31. Accessed 14 Mar 2017.

Terry Pratchett. A Hat Full of Sky. Doubleday Books, 2004.

- - - Dodger. Corgi Books, 2012.

- - . The Fifth Elephant. Corgi Books, 1999.

- - . . Guards! Guards! 1989. Gollancz, 2014.

- - - I Shall Wear Midnight. Doubleday Books, 2010.

- - . "Imaginary Worlds, Real Stories" Folklore, Vol. 111, no. 2, Oct. 2000, pp.

159-168. 21 Mar. 2017.

- - . Lords and Ladies. 1992. Gollancz, 2014.

- - . . Maskerade. 1995. Gollancz. 2014.

- - - . Men At Arms. 1993. Gollancz, 2014. 
- - - . Monstrous Regiment. Doubleday. 2003.

- - . . The Shepherd's Crown. Corgi Books, 2016.

- - - Small Gods. Gollancz. 1992.

- - - . Soul Music. 1994. Corgi. 2013.

- - . . Thud! Corgi Books, 2005.

- - - The Wee Free Men. Doubleday Books, 2003.

- - . Wintersmith. Doubleday Books, 2006.

Pratchett, Terry and Simpson, Jacqueline. The Folklore of the Discworld. Corgi Books, 2014.

Sévère, Richard. "Malory's 'Chivalric Cliques': Public and Private Felyshyp in the Arthurian Community". Arthurian Literature XXXII, edited by Elizabeth Archibald and David F. Johnson, NED, Boydell \& Brewer, 2015, pp. 105-122. Mar 21. 2017.

Silanpää, Mirka. "The Maiden, the Mother and the Other One: The Witches in Terry Pratchett's Discworld Novels." MA thesis. The University of Tampere, 2006. 14 Mar. 2017.

Sinclair, Lian. "Magical Genders: The Gender(s) of Witches in the Historical Imagination of Terry Pratchett's Discworld." Mythlore. vol. 33, no. 2, 2015, pp. 720. 14 Mar. 2017.

"Sir Orfeo". Norton College Online. 10 Aug. 2017.

Shaw, Brent D. Bringing in the Sheaves: Economy and Metaphor in the Roman World. University of Toronto Press, 2013. 14 Dec. 2017. 
Stevenson, Lionel. "The 'High-Born Maiden' Symbol in Tennyson." PMLA. Vol. 63, no. 1, Mar. 1948, pp. 234-243. 14 Nov. 2017.

Stone, Alby. "Bran, Odin and the Fisher King: Norse Traditions and the Grail Legends." Folklore. Vol. 100, no. 1, 1989, pp. 25-38. 6 Jul. 2017.

Sweeney, Mickey. "Divine Love or Loving Divinely?: The Ending of Malory's 'Morte D’Arthur'”. Arthuriana. Vol. 16, no. 2, Summer 2006, pp. 73-77. 22 Mar. 2018.

Taylor, Dennis. “Tennyson's Catholic Years: A Point of Contact”. Victorian

Poetry. Vol. 47, no. 1, Spring 2009, pp. 285-312. 17 Nov. 2017.

Tennyson, Alfred Lord. "Lady of Shalott". Poetry Foundation,

https://www.poetryfoundation.org/poems-and-poets/poems/detail/45359 Accessed 13 Oct. 2017.

J. R. R. Tolkien. "On Fairy Stories”. http://brainstorm-services.com/wcu2004/fairystories-tolkien.pdf Accessed 14 Mar 2018.

Varin, Amy. "Morded, King Arthur's Son”. Folklore, vol. 90, no. 2, 1979, pp. 167177. 12 Sep. 2017.

Weston, Jessie L. From Ritual to Romance. Doubleday Anchor Books, 1957. Wright, Jane. "A Reflection on Fiction and Art in 'The Lady of Shalott'”. Victorian Poetry. Vol. 41, no. 2, 2003, pp. 287-290. 21 Mar. 2017. 